Portland State University

PDXScholar

Spring 6-21-2013

\title{
The Role of Expectations on Nonnative English Speaking Students' Wrtiting
}

\author{
Sara Marie Van Dan Acker
}

Portland State University

Follow this and additional works at: https://pdxscholar.library.pdx.edu/open_access_etds

Part of the Applied Linguistics Commons, Bilingual, Multilingual, and Multicultural Education Commons, and the First and Second Language Acquisition Commons Let us know how access to this document benefits you.

\section{Recommended Citation}

Van Dan Acker, Sara Marie, "The Role of Expectations on Nonnative English Speaking Students' Wrtiting" (2013). Dissertations and Theses. Paper 1110.

https://doi.org/10.15760/etd.1110

This Thesis is brought to you for free and open access. It has been accepted for inclusion in Dissertations and Theses by an authorized administrator of PDXScholar. Please contact us if we can make this document more accessible: pdxscholar@pdx.edu. 
The Role of Expectations on Non-Native English Speaking Students' Writing

by

Sara Marie Van Dan Acker

A thesis submitted in partial fulfillment of the requirements for the degree of

Masters of Arts

In

Teaching English to Speakers of Other Languages

Thesis Committee:

Stephen Reder, Chair

Susan Conrad

Anne Knepler

Portland State University

2013 
(C) 2013 Sara Marie Van Dan Acker 
Abstract

This study centered on the expectations of a non-native English-speaking undergraduate student and her teacher in a general education course at Portland State University during winter term 2012. This was a qualitative case study, where I collected data throughout the duration of the course by means of interviews, classroom observations, and written assignment sheet data. I triangulated verbal data from interview transcripts from the two participants, along with data from the observation notes and the assignment sheets in order to gain a better understanding of the expectations each participant had about writing assignments.

Data from four sources were collected and analyzed: interview transcripts, assignment sheets, the course syllabus, and classroom observation notes. Interview transcripts were the primary source of data, and were triangulated with the other abovementioned data sources.

The themes that emerged from verbal interview data were categorized and then subcategorized according to theme. The first category that emerged was Assignment Expectations. This was subcategorized into: Summarize, Examples, Reflect, Critical Thinking, and Theory Application. The second category was Evaluation, which was comprised of the themes Grading and Rubric. The third category that emerged was Student Interaction With Assignment, in which six subcategories emerged: Process, Experience, Time, Reading, Preparation, Understanding, and ESL. Lastly, the category background emerged, which contained the subcategories History and Background. 
The findings of this study showed that due to the student's extensive background with various academic writing assignments prior to entering the course, she had similar expectations of specific assignment sheet attributes as the teacher. However, there were more salient differences in expectations between the teacher and the student in terms of how the student interacted with the assignment at the individual level. Likewise, expectations of assessment illustrated the murky nature of evaluation, even in a situation where the student had had extensive experience with academic writing assessment in the past. 
Acknowledgements

Dr. Stephen Reder, the chair of my thesis committee, has given me immeasurable time and input into this work, from its earliest brainstorming to its final draft. Dr. Susan Conrad, a member of my thesis committee, has offered great insight for my research throughout the thesis process. Dr. Anne Knepler, who is also on my thesis committee, advised this project greatly as well. Their contributions and support have been truly respected and valued.

My appreciation also extends beyond my thesis committee to Dr. Kimberley Brown, whom I have had the pleasure of working with on and off for seven years. Her belief in me as a student and as a professional has been a blessing, as she has always encouraged me to reach for my dreams and have faith in the work that I do. Also my gratefulness is expressed for Dr. Nike Arnold, who urged me throughout the program to explore my teaching and writing interests and continue challenging myself through various teaching endeavors. Their support as professors, colleagues, mentors, and friends has motivated me to become the best professional I can be.

Finally, my family's unending patience and understanding of me as I have been in the master's program has been invaluable. My mother, Lori Van Dan Acker, encouraged me to pursue a master's degree while I was living abroad and spent countless hours listening to my "next great plan" without judgment. My aunt, Teresa Kitamura, has also advised me throughout the master's program, especially in times when I might have 
given up. In my many days of solitude during the program while I wrote and worked on projects, my husband remained my biggest advocate.

I have gotten to this point in my educational and professional career with the help of every person mentioned above. They have all inspired me throughout this journey. For all of their support, I express my deepest gratitude. 
Table of Contents

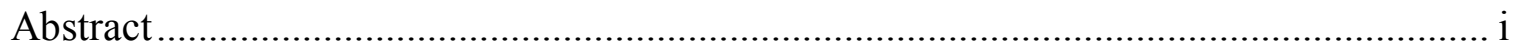

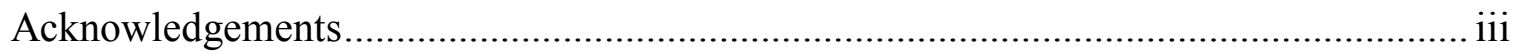

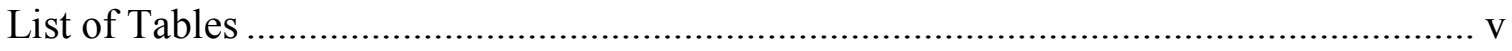

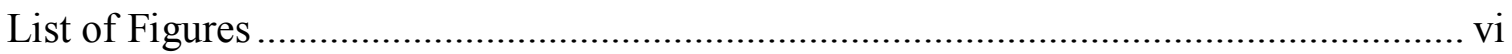

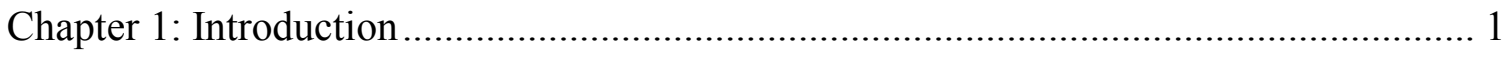

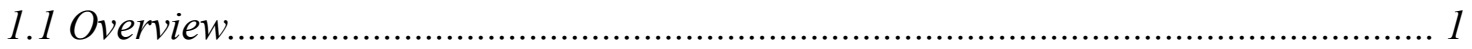

1.2 University Studies Background Information ...................................................... 2

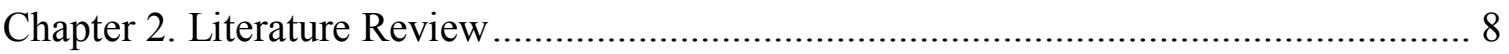

2.1 Cultural Differences in Understanding College Expectations............................... 8

2.2 Culturally Shaped Attitudes Toward Knowledge ............................................... 10

2.3 Cultural Factors that Influence the Interpretation of Assignments ...................... 12

2.4 Mismatches in Expectations of Writing Assignments ......................................... 15

2.5 Mismatches in Expectations of Assessment...................................................... 17

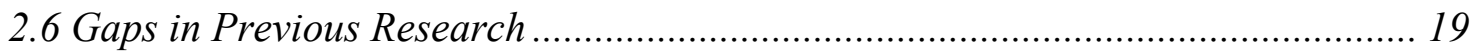

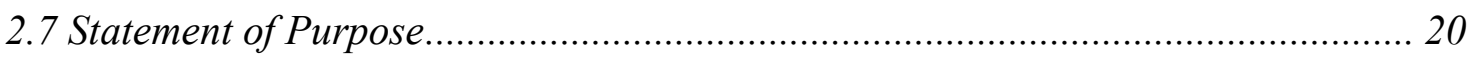

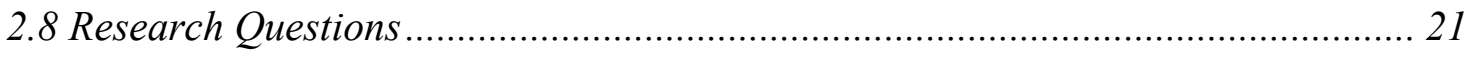

Chapter 3. Methodology and Data Collection Procedures ........................................... 22

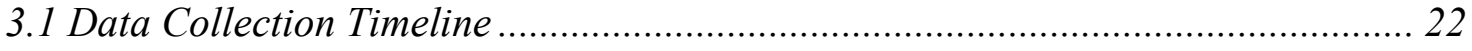

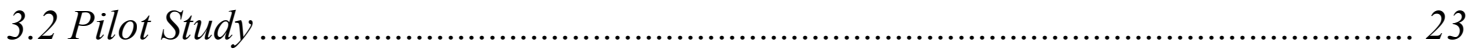

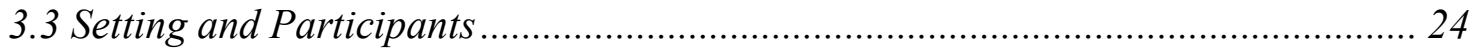

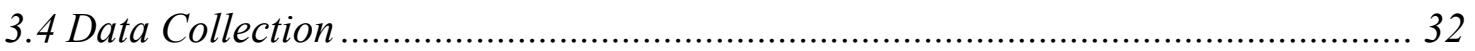

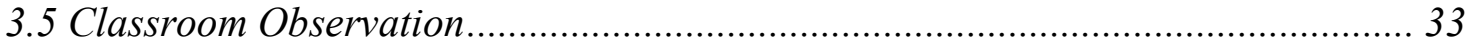

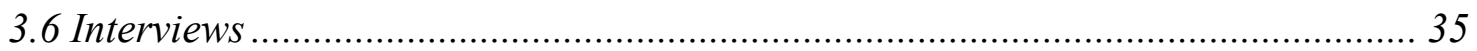

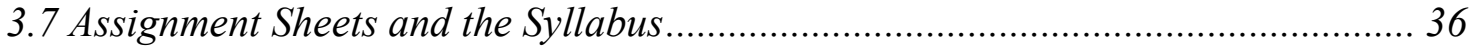




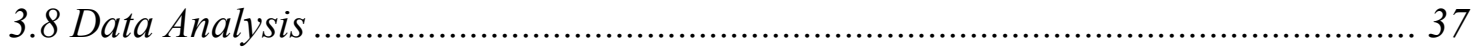

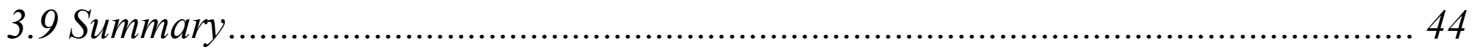

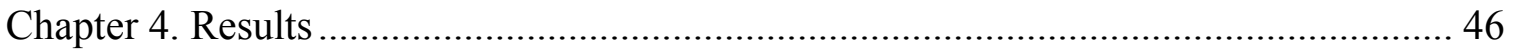

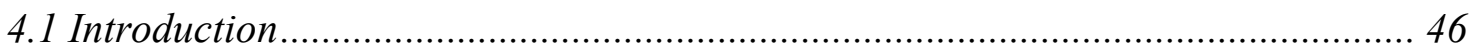

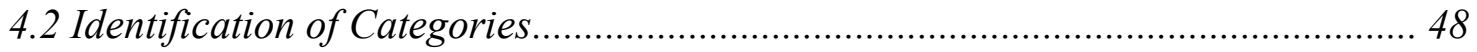

4.3 Professor Hannah's Account of Assignment Expectations ................................... 50

4.4 Ubah's Account of Assignment Expectations..................................................... 52

4.5 Professor Hannah's Account of Assessment ……………………………........ 53

4.6 Ubah's Account of Assessment .......................................................................... 57

4.7 Professor Hannah's Comments Regarding Student Strategies of Assignment

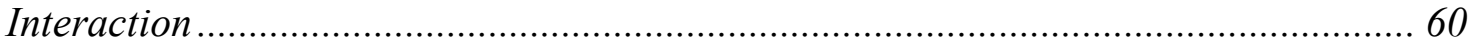

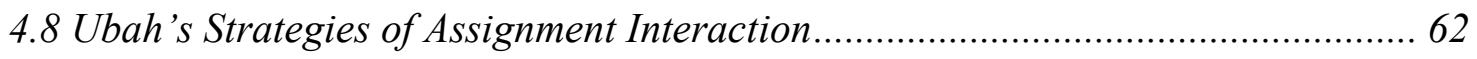

4.9 Ubah's Background Factors That Affected Expectations .................................... 67

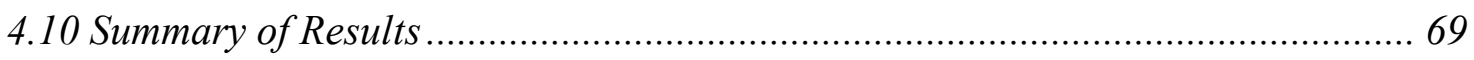

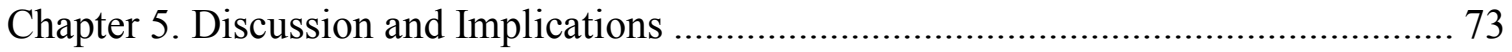

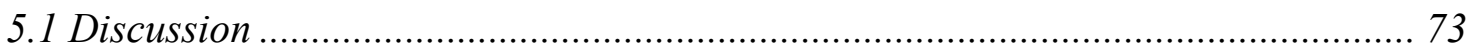

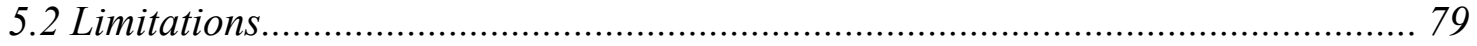

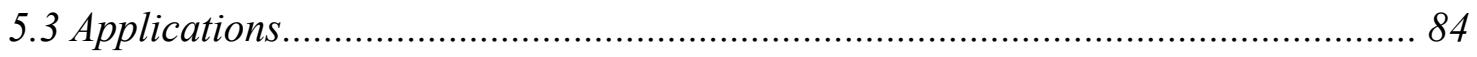

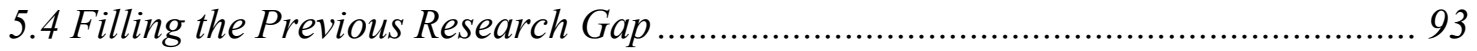

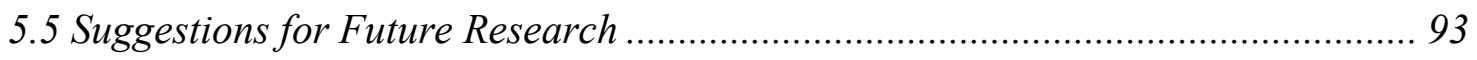

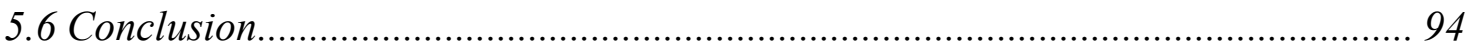

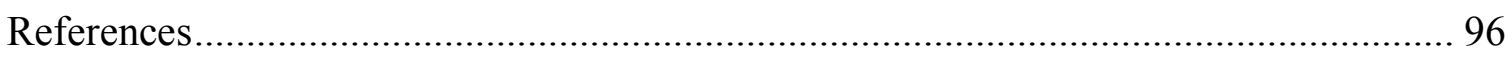

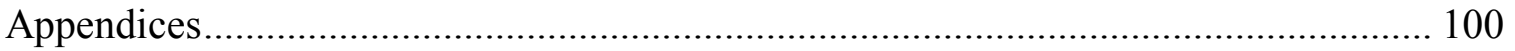

Appendix A: Coding Chart for Assignment Details …………………................... 100

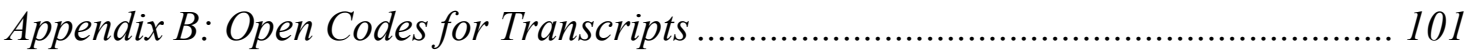

Appendix C: Categorical Chart for Transcripts ……………................................. 102

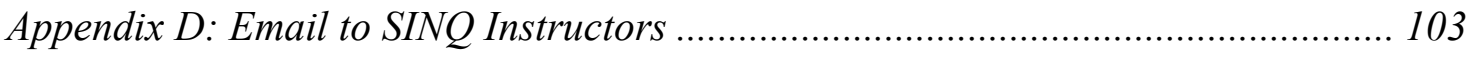


Appendix E: Questionnaire for PSU SINQ Students: ............................................ 104

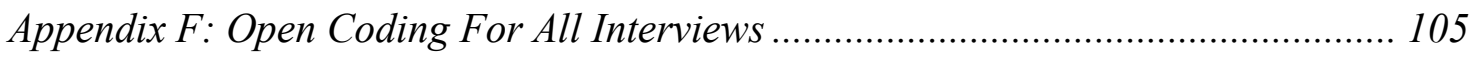

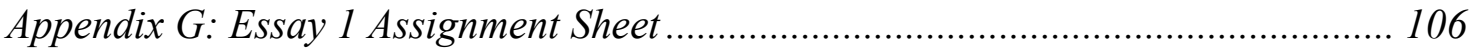

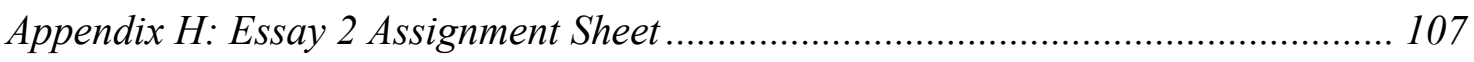

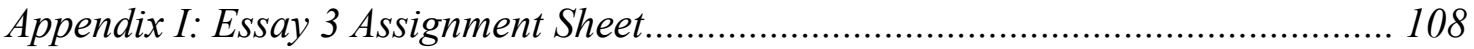


List of Tables

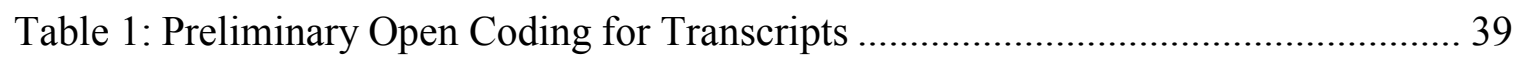

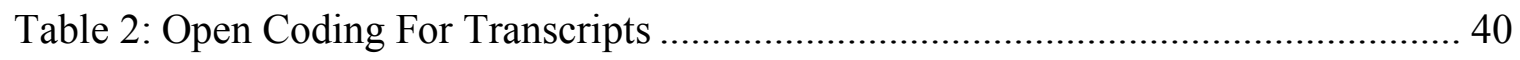

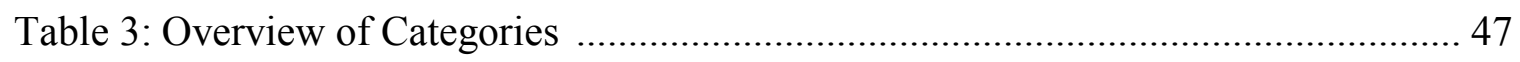

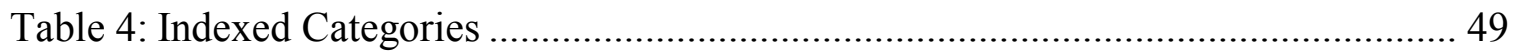




\section{List of Figures}

Figure 1: Example SINQ Student Schedule ............................................................... 3

Figure 2: Distribution of University Studies Courses .................................................. 4

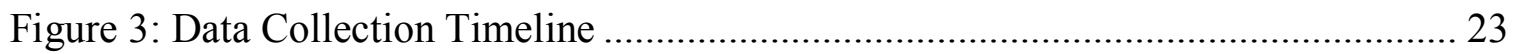


Chapter 1: Introduction

\subsection{Overview}

Oregon's largest university, Portland State University (PSU), serves a student population of nearly 30,000; approximately 22,000 of these students are undergraduates (Portland State University: Profile, 2011). Currently, there are almost 1,800 international students enrolled in classes at PSU, 1,253 of whom are undergraduates (Portland State University Office of Institutional Research and Planning, 2011). The term "international student" is defined by PSU as any student reported as a nonresident alien (Portland State University Office of Institutional Research and Planning, 2011). While the statistical information on international student enrollment includes the official count of nonresident aliens, this number does not accurately represent students who are enrolled in PSU classes but who are not nonresident aliens. This much larger and more complex population also includes students who are not international students but who are nonnative English speakers (NNES).

The population of International students (and therefore the broader population of NNES as well) continues to rise at PSU (Portland State University Office of Institutional Research and Planning, 2011). As a result, more and more NNES undergraduates enroll in general education courses alongside native English speakers (NES). Therefore, it has become increasingly important to examine issues surrounding NNES in general education courses within the university. 


\subsection{University Studies Background Information}

University Studies (UNST) is a program that houses PSU's general education courses. These courses also fulfill students' undergraduate writing requirement. They are broken up into various sequences and themes, beginning with a students' freshman year and extending to senior year. These courses are separate from classes in a student's major. During a student's freshman year, he or she takes a Freshman Inquiry class (FRINQ), which lasts an entire academic year and is based on one theme that the student selects from an array of topics that are predetermined by the university. These inquirybased classes employ an academic instructor as well as an undergraduate student mentor. Students attend two FRINQ classes per week led by the instructor, and attend one breakout mentor inquiry class per week led by the mentor.

In the second year, students transition into Sophomore Inquiry (SINQ) classes. These courses are one quarter each and students again self-select the themes they want every term from the choices available in the course catalogue. Similar to FRINQ, each course has an academic instructor and a graduate student mentor; students attend two main sessions and one mentor session per week. An illustration of an example SINQ schedule is illustrated in figure one below. 


\begin{tabular}{|c|l|l|}
\hline \multirow{2}{*}{ Time } & \multicolumn{2}{|c|}{ Day } \\
\hline \multirow{4}{*}{$11: 30-12: 45$} & Monday & Wednesday \\
\cline { 2 - 3 } & $\begin{array}{c}\text { SINQ Main Session } \\
\text { (36 Students) }\end{array}$ & SINQ Main Session \\
& & (36 Students) \\
\hline $1: 00-1: 50$ & & (12 Students) \\
\hline
\end{tabular}

Figure 1: Example SINQ Student Schedule

Sophomore Inquiry classes generally have up to 36 students enrolled in main session classes, while mentor sessions are much smaller and usually have up to 12 students enrolled. Main session classes are comprised of a variety of activities, such as lecturebased activities, small group discussions, and whole group exercises that allow students to discuss course topics and readings. Mentor sessions also focus on a variety of activities and skills such as developing computer literacy, working on writing assignments, and furthering main session discussions ("Portland State University Studies: Sophomore Inquiry Mentor Sessions,” 2011). In some cases, SINQ courses are connected to Junior Cluster courses that are taken during a student's junior year. SINQ courses are interdisciplinary, and are writing intensive in nature. 
Students who complete three SINQ courses select a Junior Cluster area from one of the themes they studied in SINQ and one class per term related to the theme they chose. These courses have more variation and do not have student mentors. However, there is some connectivity between SINQ and Junior Clusters in that there is a coordinator that oversees a particular theme for both the cluster and SINQ courses. Finally, students complete a Senior Capstone in their final year. The capstone is usually a service-based project that lasts one term. This course distribution is presented in the following figure below.

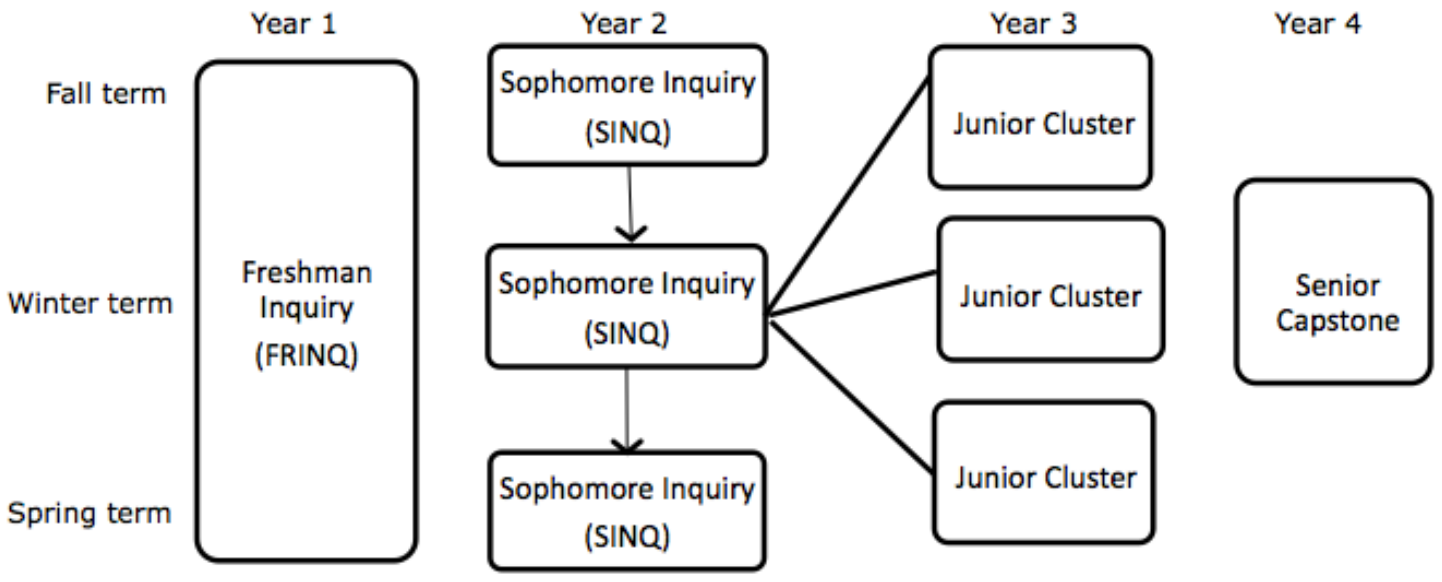

Figure 2: Distribution of University Studies Courses

SINQ courses are taught by full time University Studies faculty, adjuncts, or tenured and non-tenured faculty members in departments across Portland State University. Graduate mentors for SINQ courses come to the program having undergone an intensive hiring 
process that includes an online writing test, a quarter-long training course, and a variety of workshops and theoretical modules.

The University Studies program has four learning goals for students: Inquiry and Critical Thinking, Communication, The Diversity of the Human Experience, and Ethics and Social Responsibility ("Portland State University Studies: University Studies Goals," 2011). Outcomes are addressed formally and informally throughout SINQ courses; they are operationalized in classes through activities and discussions, and explicitly mentioned in formal end of the term surveys distributed by the department. Courses within the program are all interdisciplinary; writing is taught within the context of each course and varies among courses. Writing falls within the communication goal of the program, but is not standardized. However, some writing assignments in various SINQ courses may be similar in content. Writing in University Studies at the program level focuses on writing across the curriculum (WAC), whereby students learn a variety of conventions and ideas that are intended to prepare students for entrance into junior cluster courses. It is important to note, however, that in University Studies, writing takes place within the context of the topics in each inquiry or cluster course and is not separated as a specific course in the program.

The definition of writing in University Studies, and more specifically, in SINQ courses, is complex. Since currently there are no set requirements for writing in the program, dealing with NNES student writing becomes another complexity. The lack of consensus regarding nonnative writing in UNST courses was illuminated in a personal experience I had working as a graduate mentor in a UNST SINQ course in spring term, 
2011. During a regular weekly meeting that I had with my faculty partner, I was surprised when she suddenly slid a paper across the table toward me and said, "I'm not sure how to grade this. I was thinking that since you're an MA TESOL student and are familiar with nonnative writing you could help me grade it?" According to the instructor, the student did not follow the directions in the writing assignment to analyze a current social problem using a theory that was presented in class. At that moment I wondered how many instructors had been in a similar predicament when dealing with NNES undergraduate writing.

This is a qualitative case study that focuses on one NNES student and her teacher and explores the differences in expectations of writing assignments in a SINQ course. Based on my experience working with this population of students, I expect that the results of this study will likely show that there is not a clear line of understanding between NNES students' assumptions of specific assignment attributes. Conducting a study with this particular group of students enrolled in University Studies SINQ courses at Portland State University will illustrate the assumptions of these students toward their assignments, and the expectations of assessment that the students hold. Perhaps this will shed light on the complicated nature of writing assignments in general education courses when dealing with diverse student populations such as NNES undergraduates. In the following chapter, I will discuss previous research regarding NNES undergraduate student writing. I will highlight past related studies and describe gaps in the literature. Additionally, I will state my purpose of research and describe my research questions. In chapter 3, I will detail the study's methodology. Chapter 4 will describe the study's 
results, and finally in chapter 5 I will give a more detailed discussion and share implications of the study. 
Chapter 2. Literature Review

This literature review explores six areas of concern in the topic of NNES undergraduate student writing in university courses: cultural differences in understanding college expectations, culturally shaped attitudes toward knowledge, cultural factors that influence the interpretation of assignments, mismatches in expectations of writing assignments, mismatches in expectations of writing assessment, and gaps in previous research. Based on the literature, I designed my study, which focuses on an NNES undergraduate student and her teacher in a SINQ course. Finally, I present my research questions. Within this literature review, I argue that NNES undergraduates bring with them a set of culturally influenced skills and tools that may not always be parallel to those of their NES undergraduate peers. These skills and tools cause discrepancies between student and teacher expectations of writing assignments.

\subsection{Cultural Differences in Understanding College Expectations}

The college environment can be a place of conflict and struggle for many students. Within previous research, scholars have suggested students must master certain roles designated by society or by institutions. These roles act as resources and help students navigate through hierarchical institutions. The more resources students have, the more likely they are to succeed in academic settings (Bourdieu \& Passeron, 1990; Collier, 2001, Collier \& Morgan, 2008). 
Resources are separated into two sections: academic skills, or previous preparation in reading college texts, and cultural capital, which includes, but is not limited to the social skills necessary to recognize and respond to teacher feedback on assignments (Collier \& Morgan, 2008, p. 429). It is important to note that according to Bourdieu \& Passeron (1990), cultural capital can be gained in a variety of areas such as knowledge, education, and skills, which enable people to gain power in society and succeed in the education system. For the purposes of this study, however, cultural capital is most closely related to the social skills as mentioned before.

In a recent study, Collier \& Morgan (2008) wrote about "traditional students", or those who come from backgrounds that support the college environment- - for example, students whose parents went to college. Nontraditional students are those who may lack cultural capital. These students may be first generation college students or adult students returning to college after several years out of the academic community. In this study, NNES students also represent nontraditional students, as their ability to succeed in college is marked not only by age or backgrounds that are conducive to the college environment, but also by language as a resource, or linguistic capital (Bourdieu \& Passeron, 1990, p. 70). Students whose linguistic capital is different from the dominant language used therefore have an unequal understanding of their roles within college and how to master those roles.

In an L2 academic environment, role mastery can be particularly challenging due to students' expectations within college. Parallel to challenges that NES nontraditional first generation students face, NNES nontraditional students may also have difficulties in 
understanding workload, priorities, communication, problem-solving techniques, the syllabus, and particular assignments (Collier, 2001; Collier \& Morgan, 2008). This difference in concept interpretation ultimately stratifies students into a hierarchy of power, whereby traditional students with adequate cultural capital progress through college with fewer challenges than NNES students who must reconsider implicit meanings of concepts while simultaneously tackling the world of college. Specifically, the meanings of critical thinking and knowledge may have distinct impacts on the completion of assignments and thus success in university as a whole, as these are two concepts that are largely culturally constructed.

\subsection{Culturally Shaped Attitudes Toward Knowledge}

A portion of Portland State University's value statement reads, PSU values intellectual inquiry in its undergraduate and graduate programs, provides leadership in the development of knowledge, and creates opportunities for the application of knowledge to real-world problems ("Portland State University: Our Mission," 2011, para. 4).

This statement indicates the importance placed upon knowledge in academia. The first line, "PSU values intellectual inquiry in its undergraduate and graduate programs," while vague, describes the manner in which PSU places importance on gaining knowledge. The very word, "inquiry," is used as part of the overarching course titles, Freshman Inquiry and Sophomore Inquiry. One of the ways Portland State measures inquiry is in how students develop their knowledge and how they use it outside of the university. This can 
most easily be illustrated through PSU's service learning goal. For University Studies, as mentioned in Chapter 1, this service learning is done senior year through a capstone project within the community. In fact, the phrase, "let knowledge serve the city" is displayed on an aerial footpath that connects two buildings together on campus as well. From the mission statement stated above, PSU defines knowledge by questioning or examining the intellect and measuring that examination through community service. However, the implications of the mission statement directly affect NNES students, as the words knowledge or inquiry may not have the same meaning across cultures.

While students may attempt to negotiate their social roles in college, they must also understand what constitutes knowledge at PSU. Culturally differing attitudes about knowledge consequently influence expectations of students and teachers alike (Ballard \& Clanchy 1991, p. 21). However, this gap in what constitutes knowledge in terms of writing is often overlooked in university settings.

Critical thinking, or analysis, an important skill in American university courses that is expressed through writing, is one particular construct within the meaning of knowledge that has implications for NNES undergraduates. The ability of college students to critically analyze information presented to them in academic contexts is crucial to academic success (Ballard \& Clanchy, 1991, p. 24). However, if students bring with them a different set of attitudes toward critical thinking, they may be less prepared to succeed academically in college (Collier, 2001, p. 220).

Given that knowledge and critical thinking can be considered culturally constructed in nature, NNES college students must navigate their way through academia 
in a second language where cultural beliefs and notions of knowledge collide. Some students may go through English for academic purposes (EAP) courses or other intensive English language programs that may prepare them linguistically for writing papers in mainstream courses. However, being able to effectively negotiate the specific meanings of assignments and assessments from teachers may be blocked by distinct cultural differences stemming from the very origins in meaning of constructs such as knowledge and critical thinking (Spack, 1988, 1997). Given that assignments can be heavily influenced by culture, even if students have been trained linguistically in EAP classes to write papers, they may be a disadvantage because they still lack the cultural tools to deconstruct the cultural values embedded in writing assignments.

Although the abovementioned articles provide general insight into conflict between perceived knowledge as it relates to culture and writing, well-documented examples of NNES undergraduate students enrolled in specific general education courses that are writing intensive are not available. This is a gap in the researched literature. NNES undergraduate college students' interpretations of assignment parameters should thus be considered in order to understand the complicated nature of knowledge and academic literacy within writing; the next section highlights these interpretations.

\subsection{Cultural Factors that Influence the Interpretation of Assignments}

The cultural backgrounds of NNES undergraduate university students can affect their interpretation of writing assignments and influence the writing that they produce. With regard to essay tests in particular, Hamp-Lyons (1993) wrote about the multifaceted 
characteristics that a writer brings with him or her, including experience, knowledge, emotions, and opinions. The writer must then interconnect these notions with the assignment itself in a way that is comprehensible before attempting to produce written work (p. 52).

Since NNES undergraduates are a diverse group of students who come from many different backgrounds, their interpretations of assignments may vary more than their NES peers' interpretations. Spack (1997) stated, “L2 students do not fit into a simple stage model of development: They vary in age and background, speak different languages, and may communicate in ways that do not follow recognizable conventions" (p. 37). Parallel to this, Leki (2007) wrote,

Perhaps it is the difference between writing in a primary language and writing in a language that is not yet fully controlled or that cannot (yet) fully engage deep-seated emotional strata that are available and accessible to students writing in their L1's (p. 236).

NNES undergraduates bring a variety of resources, or cultural capital, with them to the academic institution, which then influences their interpretations of assignments and thus indicates their level of academic success (Collier \& Morgan, 2008).

Writing assignments carry embedded cultural notions and ideals, which inevitably complicate assignments for students who come from different cultures that do not share the same notions or ideals. For example, in some countries, writing indirectly or writing to avoid illustrating an opposing view from scholars and previous works are found much 
more commonly than in the United States (Angelova \& Riazantseva, 1999, p. 519), where the opposite is often necessary for the successful completion of assignments.

When NNES undergraduate students approach writing assignments, they must not only negotiate cultural differences related to content, but also ones related to rhetoric and conventions. For the purposes of this study, the term "rhetoric" encompasses the specific set of rules and principles by which a written piece must follow in order to be considered effective. Land and Whitley (1998) suggested that in order for students to achieve comparable scores on writing assignments to those of their NES peers, NNES students needed to write essays that were grammatically, syntactically, and rhetorically parallel to those written by NES students. This can be difficult for students writing in an L2 as elements of their L1 can overshadow their L2 writing, which can thus separate students from the L2 rhetorical community (p. 136). Connected to the understanding of rhetoric is the overarching notion of literacy development - understanding how language works is the crucial element necessary in navigating the ability to write (Brandt, 1990, p. 5). Therefore, culture not only affects the interpretation of assignments but also determines to which rhetorical community a student will belong and marks literacy development as a whole.

In addition to having rhetorical knowledge, Beaufort (2007) identified four other areas that make up discourse community knowledge: writing process knowledge, subject matter knowledge, genre knowledge, and rhetorical knowledge (p. 19). Students must gain knowledge in all four areas in order for them to become expert writers. Once achievement in all four areas was achieved, then students could become more successful 
members of their discourse community - in this case, members of the university. Thus, NNES undergraduates must gain the cultural capital to interpret assignments in a way that bolsters academic achievement in their courses and beyond; this aspect is crucial for NNES undergraduates to master their roles as college students within SINQ courses and across the disciplines.

\subsection{Mismatches in Expectations of Writing Assignments}

In order for NNES undergraduates to transfer prescribed cultural notions from course readings to writing assignments within general education courses that are writing intensive, teachers must have some role in preparing assignment expectations or requirements that may guide these students as they negotiate their positions within the English language and the American culture. Cultural mismatches can be particularly

problematic in American courses, as specific knowledge may be assumed. Leki (2006) reported on one such mismatch in which an L2 student in California did not know the answer to the teacher-prepared question, "What was the original name of San Francisco?" (p. 142). Because the student was not from the area and had only immigrated recently, the student was unaware of local geographic history, whereas students who had local backgrounds knew this information. The teacher had overlooked this piece, and had assumed all students would know this information since it was their shared community.

Further mismatches have occurred in studies centering on specific discourse differences. Angelova \& Riazantseva (1999) highlighted that while NNES students often thought that their instructors wished them to employ American rhetorical styles, teachers 
were mostly frustrated by students' hesitations toward asking any clarification questions regarding assignment expectations (p. 520).

Expectations of teachers have also been examined in comparing L1 and L2 writing perceptions of NNES students. In one previous body of research, there was a discrepancy between what NNES graduate students expected in courses versus what teachers did to explain assignments (Silva, 1992). In this study, results showed that students wanted more instruction on assignments, more focused assignments and materials, and more chances to practice vocabulary and grammar through writing (p. 41). This shows a more distinct difference between students' and teachers' expectations of written assignments.

In analyzing perceptions of good writing specifically at Portland State University, Brown (2002) found that first and second year writing tutors or consultants in PSU's writing center held different notions of what made good writing. Complicating this matter was the fact that various College of Liberal Arts and Sciences (CLAS) professors across PSU had opinions of good writing that contradicted those of the writing consultants and of each other in some instances (pp. 76-92). Mirroring this, research by Leki (1995) highlighted that there was a distinct lack of consensus among writing professors about writing criteria, which made the concept of "good writing" difficult to define (p. 35).

This research again points to the fact that the roles that students employ in college can have implications for NNES undergraduate students. Collier \& Morgan (2008) stated that mastering the college student role is determined by teacher evaluation of student performance, teacher assumptions and expectations, and the resources that students have 
available to use in response to teachers' expectations and assumptions (p. 428). In order for NNES students to succeed in university settings, they must not only negotiate their interpretations of assignments, but also understand teachers' expectations of assignments.

\subsection{Mismatches in Expectations of Assessment}

Teachers' expectations of assignments not only include the interpretation of the assignment itself, but also the assessment of writing assignments. This is of particular importance in the navigation of writing assignments, because once a student turns in a paper, the teacher will evaluate and issue a grade, which is the basis of the hierarchical relationship of the teacher and student. This hierarchical relationship places the teacher in an authoritative role and the student in a powerless role (Bourdieu \& Passeron, 1990, p. 111). For NNES students, this is problematic because they must learn how the instructor

will assess written work in order to align their assignment with the grading procedures of the teacher; however, the cultural capital the student brings with him or her to the classroom inevitably affects the capacity to which this may be done (Collier, 2001; Collier \& Morgan, 2008).

Evaluation is culturally constructed and may be influenced by the teacher's internalization of assessment parameters. In Vaughn's (1991) study about essay test evaluation, written work was assessed by five different grading styles that characterized approaches to rating in the following ways: the single-focus approach (focusing on one area of the essay such as punctuation), the first-impression dominates approach (using an opinions of the overall paper to evaluate), the two-category strategy (choosing any two 
categories of personal importance such as organization and grammar), the laughing rater (being generally annoyed at an essay's judged quality), and the grammar oriented-rater (focused mainly on grammatical structures and errors) (119-120). Even though all raters had a set of grading guidelines to work with, their individual grading styles and personal judgment often trumped the set guidelines. While this study focused mainly on professional and highly experienced essay graders and not specifically on instructors, the murky nature of assessment is still illustrated. Teachers and graders bring their cultural and educational backgrounds with them as they evaluate writing assignments, and what results is a situation where the grade is given, but students still do not completely understand why they received the grade because the judgments of the evaluators are not fully revealed (Ballard \& Clanchy, 1991, Land \& Whitley, 1998; Leki, 1995; Vaughn, 1991).

Often times, teachers rely on organization and compliance of rhetorical structures in essays to determine their evaluation, whether students know that or not. What is missing in that case is an overall understanding of the message being conveyed by the student. For NNES students as mentioned before, their rhetorical background may be different from those of their teachers in American universities (Ballard \& Clanchy, 1991, Land \& Whitley, 1998). As mentioned in section 2.3, these differences can affect assessment in a way that perpetuates the student as lacking knowledge in the discourse community of higher education. While the abovementioned studies target the areas of assignment and assessment expectations, it does not fully explain the role of expectations on nonnative English-speaking students' writing. 


\subsection{Gaps in Previous Research}

Although studies have explored disparities in instructor and student expectations in writing assignments, the bodies of research are not without limitations. For example, Leki's (2006) article focused on the relationship between NNES graduate and undergraduate students and cited some instances of potential mismatches but not students' specific perceptions of them. Leki's (2007) study centered on graduate students in specific programs across the disciplines. Angelova and Riazantseva (1999) wrote primarily of academic discourse communities shaping miscommunication between students and teachers. Spack (1997) followed one NNES student longitudinally throughout all of her courses to provide an in-depth analysis if this student's academic life. Silva (1999) reported on attributes in writing assignments that graduate students wanted from teachers. Brown's (2002) study pointed to differences in perceptions of good writing in the writing center, which is an optional resource at PSU that serves to support all courses on campus. Vaughn (1991) focused on essay test graders; while highly experienced; these graders were not instructors of the course. Also, it should be pointed out that the essay test (such as the International English Language Testing System) is different from take home essays. For take home essays, students have much more time to work on the essay in a less anxiety-producing environment, whereas the essay test is timed and is usually taken in a high anxiety-producing environment such as a testing center. Finally, Collier (2001) and Collier \& Morgan (2008) provided insight into the roles of traditional and nontraditional students in University Studies at Portland State University. While all of these studies present a rich description of various aspects of 
writing issues in the university context, none of them examine NNES undergraduate writing concerns within required general education courses such as University Studies SINQ courses at PSU.

In particular, NNES views of writing in UNST courses need to be examined in order to triangulate teachers' expectations, students' expectations, and the assignment itself. The research presented that involved teacher and student expectations broadly focused on a wide variety of issues surrounding NNES, their teachers, and writing. Given that all of the articles mentioned thus far span from 1988 to 2008, more recent issues dealing with NNES undergraduate students should be addressed in order to bridge this gap in research. This study compares the expectations of one NNES undergraduate student and one teacher in a UNST SINQ course by examining data from assignment sheets, interviews, and classroom observation. The gaps in previous research discussed previously will be addressed through this study.

\subsection{Statement of Purpose}

The purpose of my study is to address non-native English speaking (NNES) undergraduate writing issues at Portland State University within specific required general education classes in the University Studies Program, all of which are writing intensive in nature and fulfill the undergraduate writing requirement necessary for graduation. Within University Studies courses, I will examine a sophomore inquiry (SINQ) course, which all sophomore undergraduate students must take in their second year of college. 
Focusing on a specific group of students-NNES undergraduates at PSU enrolled in SINQ — will yield more focused and detailed insight into current issues surrounding writing. Primarily, I will be looking at expectations of students in writing. Specifically, my study will explore these questions:

\subsection{Research Questions}

1. How do the assumptions that NNES undergraduate students make about specific attributes in SINQ writing assignments compare with those of their teachers?

2. How do the expectations that NNES undergraduate students have about assessment in SINQ writing assignments compare with those of their teachers?

In chapter three, I will discuss the methodology of my study, including data collection procedures and data analysis. In chapter four, I will detail the results of my data analysis and answer my research questions. Finally in chapter five, I will evaluate my results, discuss limitations of the study, make suggestions relevant for writing assignment interpretations, and explain possible future research on the topic. 
Chapter 3. Methodology and Data Collection Procedures

In this section, I will discuss my methods for data collection in my research study. This chapter is organized chronologically. First, I will explain a pilot study that I designed and carried out in order to test my procedures prior to conducting the research

study. Following this I will describe the setting at which my study took place and several methodological choices I had to make during the selection of courses. Additionally, I will discuss the selection of participants for my study and background information about the participants. Finally, I will detail the data collection process, which included conducting interviews, examining course assignment sheets, and observing classes.

\subsection{Data Collection Timeline}

This research study spanned more than one year and entailed several steps before, during, and after the data collection. Beginning in November 2011 I first conducted a pilot study in an Applied Linguistics course. After conducting the pilot study for purposes of gaining insight into data collection procedures, I then contacted an administrator in University Studies to help coordinate classes that may work for my study. We met on two different occasions to look at enrollment patterns for previous terms and identify courses to study that would have enough students to recruit and an instructor willing to participate in the research for an entire quarter. After identifying four instructors who would potentially be interested in participating in the study, I emailed them directly and spoke over the phone with them as well. More about this will be discussed in section 3.3. I 
collected data during winter term 2012. Following this, I analyzed data from spring term 2012 to fall term 2012. A diagram of the research study timeline is displayed below in figure 3 .

\begin{tabular}{|c|c|c|c|c|c|c|}
\hline $\begin{array}{l}\text { Nov. } \\
2011\end{array}$ & $\begin{array}{l}\text { Dec. } \\
2011\end{array}$ & $\begin{array}{l}\text { Jan.- } \\
\text { March } \\
2012\end{array}$ & $\begin{array}{c}\text { March } \\
2012\end{array}$ & $\begin{array}{l}\text { April- } \\
\text { Oct. } \\
2012\end{array}$ & $\begin{array}{c}\text { Oct. } \\
2012\end{array}$ & $\begin{array}{l}\text { Oct.- } \\
\text { Dec. } \\
2012\end{array}$ \\
\hline $\begin{array}{c}\text {-Pilot } \\
\text { Study } \\
\text {-SINQ } \\
\text { Course } \\
\text { Recruit } \\
\text { ment }\end{array}$ & $\begin{array}{c}\bullet \text { SINQ } \\
\text { Instructor } \\
\text { Recruitment }\end{array}$ & $\begin{array}{l}\text {-Data } \\
\text { Collection } \\
\text {-2 Courses }\end{array}$ & $\begin{array}{l}\text { •Course } \\
\text { Selection: } \\
\text { Guiding } \\
\text { Civilizations }\end{array}$ & $\begin{array}{l}\text { - Data } \\
\text { Analysis } \\
\text { - Peer } \\
\text { Review }\end{array}$ & $\begin{array}{l}\text {-Participant } \\
\text { Refinement }\end{array}$ & $\begin{array}{l}\text { - Data } \\
\text { Analysis }\end{array}$ \\
\hline
\end{tabular}

Figure 3: Data Collection Timeline

Next, I will detail the pilot study that was conducted in fall 2012.

\subsection{Pilot Study}

Prior to beginning data collection, I conducted a pilot study within a graduate course titled, Discourse Analysis. The pilot study centered on an Applied Linguistics course that was similar to University Studies classes in that it was writing intensive and undergraduate students (both NES and NNES) were enrolled in it. The course was also similar to courses I might collect data in because I had a relationship with the instructor quite similar to the relationships I had with instructors in University Studies courses. My position was as a teaching assistant in the course; during the quarter, I had wondered if 
the students' and the teacher's expectations of one particular assignment influenced how members approached and dealt with the writing and assessment for the assignment.

For the pilot study, I recruited two volunteer participants, the teacher and one NNES student, in order to explore their expectations of writing assignment attributes in a course within the department of Applied Linguistics Data came from three sources for the study: written assignment details contained in the course syllabus, the transcript of one 30 minute face-to-face, one-on-one, audio-recorded interview with the student, and the transcript of one 30 minute face-to-face, one-on-one, audio-recorded interview with the teacher. The purpose of this pilot study was to gain a better understanding of the interview process, and coding verbal data that was emergent, as well as conduct a study that would have very similar research method triangulation: analysis of verbal transcripts, assignment sheets, and the course syllabus.

\subsection{Setting and Participants}

This study employed a case study methodology that included interview data analysis, assignment sheet analysis, and classroom observations. Since this study centered on NNES undergraduate student writing, I examined one SINQ course during winter term 2012. In Chapter 1 of this study, I explained how the University Studies program is run and the differences between courses at each academic year. For this study, I chose to study one SINQ course. I had two reasons for making this choice.

First, the duration of SINQ courses is short, at ten weeks each. Due to the relatively short amount of time students have in each SINQ course, they must negotiate 
assignment attributes and expectations in an amount of time more comparable to courses across the university in various academic disciplines. FRINQ courses on the other hand, which are three consecutive quarters, allow for more time with professors to negotiate expectations and assumptions. These courses are unlike the majority of courses in University Studies and across PSU that are one quarter each.

Second, since SINQ courses are at the 200-level, they are the last sequence before taking junior clusters and upper division courses in other fields. Therefore, SINQ courses serve as a stepping-stone to other courses. Also, students must choose one SINQ course to become their junior cluster theme, which highlights the importance of SINQ courses in UNST. Understanding student-writing concerns at the 200-level is crucial in dealing with the jump between lower and upper division courses in academic disciplines.

The selection of the specific SINQ course that I studied was made by first consulting enrollment pattern data disbursed by UNST. Consulting enrollment data aided in finding a course that has been shown to have NNES undergraduates in past quarters. This helped to ensure that I had a class to study that would have between three and five eligible participants. After examining available enrollment data online with an administrator of the in the University Studies department, I then narrowed the course and instructor options to include four courses that had instructors who might be interested in participating in a course-long study. Since I would be attending the main session, mentor session, and conducting interviews with members of the class for 10 weeks, it was important to recruit course instructors who might have been interested in participating in a research study. After discussing class and instructor recruitment with the University 
Studies department, it was decided that recruiting possible interested instructors would be more productive in my search rather than sending emails to all SINQ instructors.

Next I contacted the identified course instructors via email in order to describe my study (Appendix D). From the four instructors who were e-mailed, two instructors agreed to participate in the study and I phoned them to discuss the details of the study. Due to an initial concern about student participation, I decided to recruit students in both classes to ensure that I would have at least one NNES student participant in the study. I did this by visiting classes and distributing participant questionnaires to NNES Students (Appendix E). The two classes that I distributed questionnaires to students were titled Guiding Civilizations and Human Conditions. Initially, I intended on observing classes where assignment sheet information would be given and explained. My plan was to negotiate these times with the teachers in order to remain less intrusive to classes. In both classes I was invited to attend any number of classes at my discretion. Therefore, while I planned on only attending classes where assignment sheets would be disbursed and explained, after attending classes for two weeks I decided to attend all courses in order to recruit participants. Attending all sessions in both classes turned out to not be intrusive to students; in fact, the opposite occurred. My presence became familiar to students. It was only after my regular course attendance that students contacted me to participate. Additionally, as a result of my classroom attendance every session, I was able to ask more questions about assignments as they arose throughout the term.

Within the Human Conditions class, two NNES students took part in the study. These two students were both male international students. The instructor was an adjunct 
professor and the mentor had two years of experience as a graduate mentor. In the Guiding Civilizations class, three NNES students initially volunteered who were all generation 1.5 students but by the end of the term one resigned due to personal reasons. The instructor was a full-time experienced professor within the University Studies department. This was the graduate mentor's second term as a mentor for SINQ courses. At the end of the data collection process, I narrowed the data to one SINQ course: Guiding Civilizations. This was done as a result of the rich data collected in interviews with participants from the course as opposed to verbal data from participants in the Human Conditions class, where interviews were rather surface level.

One important observation about the student participant differences should be made: NNES students in the Human Conditions class were both international students and in the Guiding Civilizations class they were all generation 1.5 students. As noted in Chapter 1, international students are those who are studying at PSU on a student visa and will return to their home countries when school is completed. Generation 1.5 students are those who immigrated to the United States at a younger age but who have resident or citizen status. They have previous American educational experience prior to entering PSU. Undoubtedly, this made for a unique participant situation, as I had originally anticipated there being both international students and generation 1.5 students in my study. However, generation 1.5 students are a highly complex and diverse population, and research about participants in this population is relevant because of their presence within both the PSU and Portland community. 
After collecting verbal data, I narrowed participant inclusion further to focus on only participants who directly discussed the writing assignments in detail. One student participant's verbal data was not particularly relevant to the course; he often asked for help on his assignments for the class and for his other classes. For the participant, the interviews were more like tutoring sessions where I was expected to check his work rather than discussing writing assignment interpretations. Because of this circumstance, I felt that the data from this participant was unreliable and I therefore removed his data from the study.

Additionally, I discovered that the mentor did not have a significant role in terms of writing instruction or assistance within Guiding Civilizations. I had expected that the mentor would deal much more with writing, but his role was mostly organizational; during two mentor sessions he wrote on the board a possible outline template to use. No activities other than this were done to facilitate writing and questions about the essays were usually given vague answers and taken note of in order to report these back to the instructor. The instructor would then give more concrete answers in class or through email to specific students. The reason for the mentor's limited role in terms of writing assistance was due to the instructor's past experiences as a graduate mentor and with mentors - both graduate and undergraduate. An older system for University Studies had been to employ graduate mentors only from the English department. At that time, the faculty was, according to the teacher, "able to rely upon a certain level of proficiency [from mentors teaching writing]." However, in recent years this shifted so that mentors from all disciplines were hired and able to teach writing. The teacher explained, 
There's a lot of grad programs that don't require you to be a strong writer let alone being able to teach writing so yeah I really just don't do any instruction, or you know, have them do writing instruction in the mentor session, or in SINQ's too much at all, for that reason...because you just don't know what you're doing to get as a mentor like somebody who is, you know like Alice, she taught Writing 121 you know, or whatever already so I would trust her to do that well but I have another mentor who has never read theory before so I don't trust her to teach writing. Again because I think they're, yeah just without that composition background it's really, it's really hard. And it's one of those things we think anyone can do it because we devalue the humanities so much, but I know that's not true. So I play it safe and I am conflicted about that but that's kind of been my track lately.

Due to the teacher's personal philosophy of mentors teaching writing, there was not a strong presence of writing assignment interpretation or instruction for this mentor, whose background was not in composition. As a result of this minimal role in writing, the mentor mostly focused on separate activities in class including community building and critical thinking skills. Because of the separation between the mentor and writing assignments, there was also very little relevant verbal data from this participant. I did not find the mentor's data significant to the study so he was removed from the study.

As part of minimizing researcher bias, eliminating the mentor from the study was an important methodological decision that I made. I originally came to this research topic as a former graduate mentor, and I had assumed that all mentors would have a strong role in terms of writing guidance and assignment interpretation. I carefully bracketed my former position within University Studies by reflecting about my past role within the 
department. As Creswell and Miller (2000) describe, researchers should "bracket or suspend [their] researcher biases as the study proceeds...and reflect on the social, cultural, and historical forces that shape their interpretations" (p. 127). Since I had come to the project as a former mentor and had assumed that the mentor would have a role in dealing with writing assignments, I spent a great deal of time pondering the role of the mentor. I took reflective notes before and after interviews. I then reflexively approached the notes and the data from interviews to examine the data along with my reflections of the data. Also, I brought my reflective notes to peer review sessions in a graduate thesis research course I was enrolled in during winter 2012. I often consulted with members of the Applied Linguistics department to examine data interpretations from interviews. After analyzing data and discovering that the mentor did not in fact have a significant role in assignment interpretations, the removal of that participant's data provided a more representative portrayal of how the class operated. Removing the mentor from the analysis also enhanced the credibility of the research study, through bracketing and researcher reflexivity, as mentioned previously. The implications of the lack of mentor involvement are discussed further in chapter five.

Following the above-mentioned participant narrowing, the final selection of participants consisted of the teacher (Hannah) and one NNES student (Ubah) from the course. 


\section{Ubah}

Ubah was a 19-year-old female student who was from Somalia. This was her first year at Portland State University, though she took classes at a community college during her senior year of high school. Ubah moved to Portland with her family in 2006, after having spent time various countries as a refugee. She was a multilingual student, speaking Somali, Swahili, Arabic, and Ethiopian. She learned English beginning in the eighth grade after coming to Portland. In addition to being a generation 1.5 student, Ubah was also a first generation college student. As the oldest child of nine in her family, it was necessary that she remained at home while in Somalia to take care of her siblings, rather than attend school. Her highest level of education in her home country was the fifth grade. During high school in Portland, however, Ubah achieved academic success and joined the Senior Inquiry program, a program that prepares students to enter universities by working on skills such as critical thinking, writing, argumentation, analysis, research, and university literacy. The credit earned from the Senior Inquiry program transferred as FRINQ credits, and therefore she was able to begin SINQ courses as a freshman. This was Ubah's second SINQ course this academic year, as she had taken her first course in the fall quarter. Ubah had also earned a scholarship based on academic merit, and was attending Portland State University with the help of those funds. She lived on campus in a dormitory and took full time classes at the time of this study. 


\section{Hannah}

Hannah was an experienced full-time University Studies professor in her midthirties. At the time of this study, Hannah had been teaching SINQ courses for several years and had been in various administrative roles within the department during this time. She had also taught FRINQ and cluster courses as well. Hannah had training and experience from the humanities, political science, and the social sciences. She pursued her graduate training at Portland State University, and also had experience as a SINQ mentor while she was a graduate student. Hannah was multicultural and multilingual, and had also been a first generation college student.

\subsection{Data Collection}

Throughout the data collection process, I triangulated data by using one-on-one interviews that were conducted in-person and audio-recorded, assignment sheet and syllabus data, and classroom observation throughout the term. Writing samples by Ubah were not included in the scope of the study. While I initially planned on attending only those classes where assignments would be discussed in class, it turned out that observation of all main session courses proved to be more beneficial, due to the unpredictable timing of questions that were raised in class by students regarding writing assignments. The teacher and students often briefly mentioned assignments, rather than having only set times dedicated to the assignment discussion. Additionally, I used assignment sheets to compare interview and observation data with the written text in corresponding assignment details. Originally I planned on also using assignment-grading 
rubrics to compare assignment expectations. I had envisioned rubrics to be written documents of expectations, but I discovered that the grading rubrics and grading criteria were often ambiguously verbalized in interviews but not given out in class. This also illustrated the importance of classroom observation. Finally, I planned to correspond with the University Studies department during winter term to incorporate additional survey questions on the end-of-the-year surveys that all UNST students are required to take. This became unnecessary, as the program added questions on its own regarding students' language use at home. Adding more questions related to language seemed redundant at that point in time. Therefore, I did not collaborate with the department regarding survey questions.

\subsection{Classroom Observation}

Classroom observation proved to be an invaluable aspect of my data collection. I first intended to observe selected main sessions and mentor sessions based on the timing of writing assignments. I planned on observing those classes in which assignments would be explained in class or days that writing would be worked on specifically within the class period. Through this selected observation, I had hoped to learn how the verbal explanations may be interpreted differently by the student. I also hoped to learn how

questions were answered in class. Since the Guiding Civilizations class met only once a week, however, I learned that observing all main session courses was necessary. Questions about assignments were taken almost every class time. Announcements about 
essays were also made during most class lessons. Additionally, verbal grading criteria were often given in class sessions, and not on written documents.

Within the main session observations, I sat in the back of the room and took notes of the lesson using a laptop computer rather than using an audio tape recorder, in order to minimize researcher presence in the classroom. I positioned myself away from the mentor and in the back of the classroom so as to not be considered a mentor or teacher in the classroom. Since I was able to attend all of the main session classes, member checking was done either after class or during interviews, to clarify what had been said in class or what was written on the assignment sheets. Clarifying information with the participants allowed for a more thorough triangulation of data, whereby I could ensure that my observation notes contained information from class that was correct.

Observations of mentor sessions were scarcer than main sessions. Since the mentor did not focus mentor sessions on writing so much as critical thinking, I only observed classes when the mentor specifically mentioned he would be working on writing or fielding questions from the assignment expectations. Those sessions were audio recorded, as the class group size was much smaller and by the time I had done my first observation, students had become familiar with my presence. Therefore, the audiorecorder was less intrusive for the class. Again, a constant comparison method was used to analyze verbal data side by side with classroom observation field notes, where verbal data comprised the primary data source and field notes were examined alongside the verbal data. 


\subsection{Interviews}

Interviews were conducted in hour-long one-on-one sessions that were taperecorded. They were initially to take place once after the participants have volunteered for the study, after every assignment has been handed out, and once at the end of the term. In total, I had expected for there to be three interviews per participant, since the Directing Civilizations course had three major writing assignments. While this plan seemed to be feasible when the research study began, factors such as busy schedules and when the student began working on the assignment impacted the timing of interviews. During the interview process, I discovered that conducting interviews immediately after assignments were handed out did not always best suit the student; she needed time to look at the assignment sheet on her own before coming to the interview. Therefore, of the three interviews, two of them took place after the student handed in the assignment. At that time, the student discussed the assignments in great detail.

Additionally, one outside factor affected interviews with the teacher. During our second interview, there was a fire alarm on campus. Everyone in the building was required to evacuate, causing our interview to be cut short. As a result of this interference, two assignments were discussed in the second interview, which would have been separate interviews had it occurred under normal circumstances.

The purpose of the one-on-one interviews with NNES undergraduates was to ask them about their assumptions about specific attributes on assignments and how they expect to be assessed in their writing on the particular assignments. Likewise, the 
purpose of one-on-one interviews with the teacher was to ask about what assumptions she had about the assignments and how she would assess students.

\subsection{Assignment Sheets and the Syllabus}

Assignment sheets and the syllabus were used in addition to interview data and classroom observation notes in order to triangulate the data collection and analysis process. Assignment sheets were used in each interview so that the participant could refer back to the written document that explained the assignment expectations. Questions about specific attributes were used in interviews that directly correlated to assignment sheet details. The example below illustrates typical questions in which participants would directly consult the assignment sheet or syllabus to answer the questions:

Please rate the following assignment components, in order of importance $(1=$ most important, 5=least important).

○ Content

- Analysis

○rganization

○ Details/Evidence

- Format/Mechanics/Grammar

Are there any words or phrases that stand out to you in the assignment sheet?

How much of your final grade is this assignment worth?

What questions do/did you have about this assignment sheet?

How did you/will you complete this assignment? 
Assignment sheets and the syllabus were used as a secondary means of data analysis; first verbal data were analyzed in order to allow the participants to illustrate their expectations and interpretations of the course writing assignments. Assignment sheets have been included as appendices for this study (Appendices G, H, I). The course syllabus, however, is not included as an appendix in order to preserve confidentiality.

I used a constant comparison method to analyze data from interviews side by side with data from assignment sheets. I did this first by organizing hard copies of the transcripts chronologically in a binder. Hard copies of assignment sheets were organized in a separate binder. Notes and reflections were contained within a bound journal. The two binders, journal, and a separate notepad were used simultaneously in order to triangulate the separate data sources. Data analysis was done in this manner, whereby I checked multiple data sources and kept detailed notes on emergent patterns and trends within the data and recorded them accordingly.

\subsection{Data Analysis}

Data analysis centered on interview data first, followed by assignment sheet data and data from observation notes. After interviews were conducted, I took notes about the interview. General thoughts, reactions, and follow up ideas were noted. I then transcribed the interviews as close to the interview date as possible using transcription software on the computer and a foot pedal. After transcribing I made detailed summaries of each interview in order to organize the data and analyze general concepts. If needed, I performed member checks via email for any necessary clarification of verbal data. I first 
analyzed the transcripts and summaries to glean general categorical concepts emergent in each interview. This was done generally at first by emergent patterns and themes. I hand tallied the number of times a participant mentioned a broad concept until a number of concepts or themes emerged. I then developed an open coding system for the data, which consisted of broad categories listed on a table. As mentioned previously, the pilot study I conducted prior to this research study broadened the way I thought about data coding and I learned that the categories would likely expand in analyzing the verbal data. In this research study, Assignment Expectations, the first category, and Evaluation, the second category, expanded substantially as themes and patterns emerged. Likewise, the second two categories were emergent in the data. Table 1 below was used for making hand tallies and for refining the open codes as themes emerged. Next, I will discuss the specific coding refinements I made as a result of the rich verbal data that emerged in this study. 
Table 1: Preliminary Open Coding for Transcripts

\begin{tabular}{|c|c|c|c|}
\hline Category / Subcategory & Code & $\begin{array}{c}\text { Participant } \\
\text { Tally }\end{array}$ & $\begin{array}{c}\text { Participant } \\
\text { Tally }\end{array}$ \\
\hline Assignment Expectations & ASE & & \\
\hline$\bullet \quad$ Summarize & SUM & & \\
\hline$\bullet \quad$ Examples & EXA & & \\
\hline$\bullet \quad$ Reflect & REF & & \\
\hline$\bullet \quad$ Critical & ANA & & \\
\hline$\bullet \quad$ Theory & CRI & & \\
\hline$\bullet \quad$ Organization & THE & & \\
\hline Evaluation & ORG & & \\
\hline$\bullet \quad$ Grading & EVA & & \\
\hline$\bullet \quad$ Rubric & GRA & & \\
\hline ST Interaction with Assignment & RUB & & \\
\hline$\bullet \quad$ Process & SIA & & \\
\hline$\bullet \quad$ Experience & PRO & & \\
\hline$\bullet \quad$ Awareness & EXP & & \\
\hline$\bullet \quad$ Time & AWA & & \\
\hline$\bullet \quad$ Reading & TIM & & \\
\hline$\bullet \quad$ Preparation & REA & & \\
\hline$\bullet \quad$ Personal & PRE & & \\
\hline$\bullet \quad$ Understanding & PER & & \\
\hline$\bullet \quad$ ESL & UND & & \\
\hline Culture & ESL & & \\
\hline
\end{tabular}

During the beginning stages of the data analysis, more subcategories under each overarching category emerged, as shown in the table above. Within the category of Assignment Expectations, the subcategory Analyze was eliminated due to the fact that it was extremely similar to Critical Thinking in the verbal data. Additionally, the subcategories Awareness and Understanding within the Student Interaction with Assignment category were combined because the verbal data corresponded more concretely with the subcategories Process, Experience, Time, Reading, and Preparation. A new category Background was created. Within this category, History was added along 
with Education. Culture was removed as a category because it undoubtedly influenced all aspects of the course, the expectations of the student, and the expectations of the teacher and thus could be seen as an overarching notion to all categories and subcategories listed in the open codes. The final open coding system that emerged from the interview data is shown in the table below. Please see Appendix F for the complete open coding system with data included.

Table 2: Open Coding For Transcripts

\begin{tabular}{|c|c|c|c|c|c|c|c|c|c|c|}
\hline Category / Subcategory & Code & $\begin{array}{c}\text { H } \\
\text { Total }\end{array}$ & H1 & H2(a) & H2(b) & H3 & $\begin{array}{c}\text { U } \\
\text { Total }\end{array}$ & U1 & U2 & U3 \\
\hline Assignment Expectations & ASE & & & & & & & & & \\
\hline - Summarize & SUM & & & & & & & & & \\
\hline - Examples & EXA & & & & & & & & & \\
\hline - $\quad$ Reflect & REF & & & & & & & & & \\
\hline - Critical Thinking & CRI & & & & & & & & & \\
\hline - $\quad$ Theory Application & THE & & & & & & & & & \\
\hline - Organization & ORG & & & & & & & & & \\
\hline Evaluation & EVA & & & & & & & & & \\
\hline - Grading & GRA & & & & & & & & & \\
\hline - Rubric & RUB & & & & & & & & & \\
\hline $\begin{array}{l}\text { ST Interaction with } \\
\text { Assignment }\end{array}$ & SIA & & & & & & & & & \\
\hline - Process & PRO & & & & & & & & & \\
\hline - Experience & EXP & & & & & & & & & \\
\hline - $\quad$ Time & TIM & & & & & & & & & \\
\hline - $\quad$ Reading & REA & & & & & & & & & \\
\hline - $\quad$ Preparation & PRE & & & & & & & & & \\
\hline - Understanding & UND & & & & & & & & & \\
\hline - ESL & ESL & & & & & & & & & \\
\hline Background & BAC & & & & & & & & & \\
\hline • History & CUL & & & & & & & & & \\
\hline - Education & EDU & & & & & & & & & \\
\hline
\end{tabular}


Within each interview transcript, when a participant discussed one of the topics listed in the table, a code next to the passage was marked, or indexed. The following quote from the NNES student participant provides an example: “ $<$ EVA $><$ GRA $>$ I don't know how much it's worth. It didn't say." Here, the quote is coded in the category evaluation and in the subcategory grading. Each transcript was analyzed in this manner, whereby the participants' comments were coded for themes. After transcripts were coded for themes, I manually counted the number of times the thematic codes were indexed within each interview. The columns in the table represent the interview. For example $\mathrm{H}$ total is the total number of thematic codes in all interviews. $\mathrm{H} 1$ is the first interview with the instructor (Hannah), and so on.

Each open code represented a theme from the verbal data, as mentioned previously. Descriptions of the open codes are as follows:

\section{Assignment Expectations}

The participant identified the categories (summarize, examples, reflect, critical thinking, theory application, or organization) as being elements necessary for the successful completion of assignments. These were identified by speech or by prompts from the interviewer while looking at the assignment sheet during the interview.

Summarize was indexed any time the participants commented on the need to summarize the course text in the assignment.

Examples was marked when the teacher or student discussed using examples, quotes, or evidence from the text. 
Reflection was marked when the teacher or student discussed using personal experience in the writing assignment.

Critical Thinking referred specifically to students needing critical thinking or analysis skills to complete the assignment.

Theory Application was in reference to any time the teacher or student mentioned using theories in the assignments.

Organization was indexed when either participant discussed the requirement of organization or how one would organize the writing assignment.

\section{Evaluation}

The participant made explicit mention of the rubric or how the teacher would be grading the essay.

Rubric was marked when the student or teacher referred to a specific set of guidelines that the teacher would use.

Grading meant any mention of assessment or grading from participants.

\section{$\underline{\text { ST Interaction with Assignment }}$}

This category represented student mental preparation or interpretations of assignments. Process was how the student or teacher remarked on how the student should go about tackling the assignment, such as outlining or synthesizing. Experience was marked when the participant commented on having expertise or practice writing this type of assignment previously. 
Time meant how long the participant worked on the assignment or how long the teacher expected students to work on the assignment

Reading referred to the specific course textbook and its relation to the writing assignments

Preparation was how the student remarked on her preparation within the course in writing the paper, as well as the instructor's expectations with how a student should prepare to write the assignment.

Personal referred to any personal stories or information to be written in the assignments. Understanding was marked when a student specifically commented on her understanding of the assignment expectations.

ESL referred to how the participant felt that being a nonnative English speaking student directly affected the student's or the instructor's interpretation of the assignment.

\section{$\underline{\text { Background }}$}

In building rapport and throughout the term, participants commented on how their backgrounds may have affected their current situations. This category therefore consisted of two subcategories: history and background.

History referred to the family experiences that prepared or did not prepare Ubah for entering the SINQ course and completing assignments.

Education referred to her educational background, including Senior Inquiry, that prepared or did not prepare her for the SINQ course and completing assignments. 


\subsection{Summary}

Data collection for this research study included a number of different procedures. I first conducted a pilot study to test interview techniques and use similar research methods to my planned research study in order to increase credibility and minimize any preconceptions I had about the potential SINQ course that I would work with. I then began data collection procedures for the research study. I recruited the course and instructor with the assistance from University Studies administration. Following this, I collected data in two SINQ courses: Guiding Civilizations and Human Conditions. Data came from classroom observations, written assignment sheets gathered throughout the quarter, the syllabus, and verbal interviews that were transcribed and coded into categories or themes that emerged from the data sources. After I collected data within the SINQ courses, I narrowed the data to include only the course, Guiding Civilizations.

I began data analysis first by hand tallying emergent thematic patterns. The emergent patterns comprised the open coding that was developed extensively from preliminary stages of analysis to advanced stages of analysis. After I began data analysis, it became apparent that some of the data from participants, namely the mentor and one NNES student, was not rich. Therefore, I refined participant inclusion to one NNES student and her teacher. This difficult methodological choice was made after triangulating data from the various sources, whereby I used a constant comparison method to simultaneously compare transcript data, interview notes, observation notes, and assignment sheet data. The data, largely emergent, produced four large categorical themes, each with subcategories within them. The first category was Assignment 
Expectations, with the subcategories of Summarize, Examples, Reflect, Critical Thinking, Theory Application, and Organization. The second category was Evaluation, which contained the categories Grading and Rubric. The third category was Student Interaction with Assignment, which included Process, Experience, Time, Reading, Preparation, Understanding, and ESL. The last finalized category was Background, which included History and Education. In the next chapter, I will discuss the results of the study and how they relate to my research questions. 
Chapter 4. Results

\subsection{Introduction}

Within the Guiding Civilizations course, there were three major written assignments and one minor reflection paper at the end of the quarter that explained to the teacher what was done in a group presentation. Because the reflection paper was connected to the presentation project and received no formal grade, data gathered from the three major written assignments were analyzed only. In this chapter, within section 4.2, I will illustrate the coded data as a side-by-side comparison between participants. As illustrated in the comparative table, four categories (themes) resulted from my research study_Assignment Expectations, Evaluation, Student Interaction with Assignment, and Background. These categories were expanded and developed through their subcategories as themes and patterns emerged in the data. Student Interaction with Assignment and Background were largely emergent through this study and were also developed through their subcategories as data emerged and were analyzed throughout the study. Within the first category, Assignment Expectations, six subcategories were generated. The second category, Evaluation, encompassed two subcategories. The third, Student Interaction with Assignment, contained seven categories, and the fourth category, Background, produced two subcategories. The table below illustrates these categories. 
Table 3: Overview of Categories

\begin{tabular}{|c|c|c|c|}
\hline $\begin{array}{c}\text { Assignment } \\
\text { Expectations }\end{array}$ & Evaluation & $\begin{array}{c}\text { Student Interaction with } \\
\text { Assignment }\end{array}$ & Background \\
\hline Summarize & Grading & Process & History \\
\hline Examples & Rubric & Experience & Education \\
\hline Reflect & -- & Time & -- \\
\hline Critical Thinking & -- & Reading & -- \\
\hline Theory Application & -- & Preparation & -- \\
\hline Organization & -- & Understanding & -- \\
\hline-- & -- & ESL & \\
\hline
\end{tabular}

Section 4.2 is a summary of the categories and subcategories, and how they relate to my research questions. Following the comparative table, I will then provide accounts from the professor, Hannah, and the student, Ubah, in sections 4.3-4.9, regarding the expectations of the assignment and assessment. Each section represents one participant's account of the stated category or theme. For example, in section 4.3, I discuss Professor Hannah's Account of Assignment Expectations, which is also the first category or theme given in the side-by-side list in section 4.2 .

The second category, Evaluation, addresses my second research question about assessment expectations. While the first category, Assignment Expectations, does, in part, address my first research question about specific attribute expectations of assignments, what emerged were the last two categories within the verbal data-Student Interaction with Assignment, and Background, which address my research questions 
more fully. These points will be discussed within this chapter and I will then provide an overall chapter summary of the results.

\subsection{Identification of Categories}

The results of the seven interviews with Hannah and Ubah produced a total of four categories related to writing assignments with subcategories that better represented each participant's verbal discussions. The number of times a participant referred to a particular subcategory or category ranged from zero to 62 . The following lists show these results. The lists are organized by participant and contain an index number, or count number, of 0-62 for each item produced by the participant. As discussed in chapter three, the categories and subcategories emerged through verbal interviews whereby the participant would mention specific notions or issues regarding to assignment sheet expectations and evaluation expectations. When the participant made such a remark, an index was manually recorded using an Excel spreadsheet. These indices were crosschecked multiple times by using the interview transcripts along with notes taken during the interviews. The indices were then compiled to create the total number of indices within each category and subcategory. These totals were also then recorded manually into a new Excel document, which is presented below. 
Table 4: Indexed Categories

\section{Hannah}

1. Assignment Expectations (40)

- Summarize (13)

- Examples (13)

- Reflect (17)

- Critical Thinking (4)

- Theory Application (4)

- Organization (13)

2. Evaluation (12)

- Grading (6)

- Rubric (6)

3. Student Interaction With Assignment (36)

- Process (10)

- Experience (2)

- Time (10)

- Reading (15)

- Preparation (2)

- Understanding (4)

- $\operatorname{ESL}(6)$

4. Background (27)

- History (27)

- Education (27)
Ubah

1. Assignment Expectations (41)

- $\quad$ Summarize (14)

- Examples (17)

- Reflect (17)

- Critical Thinking (3)

- Theory Application (4)

- Organization (13)

2. Evaluation (22)

- Grading (22)

- Rubric (0)

3. Student Interaction With Assignment (62)

- Process (28)

- Experience (2)

- Time (12)

- Reading (19)

- Preparation (1)

- Understanding (29)

- ESL (8)

4. Background (52)

- History (44)

- Education (36)

Within the Guiding Civilizations course, grades were based on 100 points and were divided into Discussion (40), Essay 1\&2 (30), Final Essay (15) and Leadership Project (15). A brief (one line) description for each assignment was given in the course syllabus. A separate assignment sheet was given out for each essay, which gave more information for the essays.

In the next section, I will discuss the results from interviews with the participants about their expectations of writing assignments, which will answer the research question, 
how do the assumptions that NNES undergraduate students make about specific attributes in SINQ writing assignments compare with those of their teachers?

\subsection{Professor Hannah's Account of Assignment Expectations}

Overall, Hannah thought the assignments in Guiding Civilizations were very clear-cut. Hannah commented in the first interview, "These assignments, as long as you engage with the reading at some level, are really very straight-forward...they need to use examples from the text at the most basic level what they're illustrating to me is that they have read the text." There were two course books used over the term in sequence. The first book, a rather long and detailed text, was used in conjunction with Essays 1 and 2. The second book was used for examples in Essay 3. Hannah spoke directly of the assignment sheet expectations with an index mark of 40. The highest number within this category was Reflect. From the assignments, Hannah explained students should use personal experience to connect their examples from the text. She remarked in the first interview,

Right now they're starting out really simple and I'm just asking them what they found interesting. So it's kinda the most primary type of reflection. You know, what did you find interesting. And then in the next one, I'm asking them to actually draw on personal experience outside of the text of the book and combine it with the text and then the third one, they'll do, all of it and then make a statement at the end, a conclusion.

In the assignment sheets, some words and phrases were displayed in bold font. She explained the following: 
The ones I bold are the things I find students struggle with doing the most. So, like when you look at my copy, and how I talked about it in class, I actually highlighted different things to emphasize...discuss, and things like that. What I find students lack the most when they come in, is this ability to pull specific examples from a text as evidence for what it is they say they think. And so that's they all have to do it. Have examples from the text. Examples from the text. Examples and quotes from the chapters. Specific examples from the text. So that's why I emphasize those because those, that's what I see the least of in not just this class but just in writing in general is the hardest thing for students to do cause that's when you get just that statement of opinion. I liked it. I didn't like it. It's like, well, what did you find - you know I'm asking them instead what did you find interesting, show me what is interesting about that.

Discussion of summarizations and using examples from the textbook were indexed 13 times each from the verbal data, which provided the second highest indices from Hannah within the category of Assignment Expectations. Field notes from class also confirmed Hannah's expectation of using examples, as she explained, "If you do not use quotes, you won't pass the assignment...using evidence is true for every class whether it's history, math, or social science - they all use and need evidence." For Hannah, the three most important parts components of the three written assignments were accurate summaries, thorough use of examples and quotations, and personal reflection linking the students' lived experiences to the text. Next, Ubah's assignment interpretations will be discussed, with regard to the results from the subcategories previously reported. 


\subsection{Ubah's Account of Assignment Expectations}

As mentioned previously, coding indices were similar for Hannah and Ubah, at 41 and 40 in the category Assignment Expectations. For the subcategories of Summarize, data from Ubah's interviews produced only one more index, at 14. Examples had five more indices, at 17, which show that using examples was an element of the assignment sheet that Ubah thought to be of importance for successfully completing the assignments. An example is a passage from the first interview with Ubah,

Well the main thing she's going to look at it is if we really did what the assignment requires. She's going to obviously look if we did all the first part and the second part and how we related to the readings, the examples we used, and like the more quotes and the more information you use from the reading is the more that she will know that you actually did that reading and you understand and so basically she's just looking how the if we did the requirements of the assignment.

Similarly to Hannah, Ubah remarked specifically about the bold font words in the assignment sheet by stating,

You need to use examples from the text in order to get full credit in this assignment like she wants, the reason why I think she puts this word [in bold] is just to see us clearly that she needs for us to use quotes in everything we said so she knows that we did the reading and again understand.

The word "example" on the assignment sheet written in bold font signified to Ubah that this was an important attribute of the assignment sheet, which meant that there was a connection between her understanding of the material and her written work. No mention in the interview data was made about how to use a quote or how to connect opinion with 
examples; She instead reiterated the importance of using examples, as the assignment sheet had.

Critical Thinking had similar indices at 4 and 3, and Theory Application also emerged 4 times for each participant. Likewise, Organization had the same count for both participants, at 13. This data suggest that in the category of Assignment Expectations, results were fairly comparable with similar or same counts of thematic patterns within the verbal interview data. Hannah and Ubah had similar ideas of what exactly was expected in the three written assignment sheets. More about this result will be discussed in section 4.8 as it relates to Ubah's interaction with the assignments. The next section will detail Hannah's and Ubah's expectations of assessment for the written assignments and will answer my second research question, how do the expectations that NNES undergraduate students have about assessment in SINQ writing assignments compare with those of their teachers?

\subsection{Professor Hannah's Account of Assessment}

Within the verbal data from interviews with Hannah, assessment (coded as the category Evaluation), emerged 12 times, which were divided equally between the subcategories of Grading (6) and Rubric (6). For Hannah, the two were inseparable, as she discussed physically using a rubric, or guidelines for assessment in order to grade the students on their written work. What is striking in this account, however, is the physical presence of the rubric. The following passage, where $\mathrm{I}$ is the interviewer and $\mathrm{H}$ is Hannah, illustrates, 
I: How will you, evaluate the assignment?

$\mathrm{H}: \quad$ I break each piece out from whatever assignment I'm using and make a rubric that I actually put up next to me or in front of me, as I look at each paper. I'm like did they do this? Yes No Yes No Yes No. And then, it's how well did they do it? Did they do it very well? Did they do it adequately, or did they do it really badly? And then I also take into consideration these things: Formatting, have they followed through, did they edit, did they proofread it? You know that type of stuff. So my primary $90 \%$ of the grade is based upon content and $10 \%$ is upon more finished, finer points of language. So a student who writes reasonably... often can get like an A-, because the content is so good.

I: Do you give a student a copy of the rubric?

H: No, I write it up on the board, when I hand them back. And I kind of explain it. I've done that before with some assignments, and it just doesn't seem to connect with the students. It just seems kind of like a waste of paper. So that's why I just kinda do it up there once and explain it. And always I kinda toy around, there are other assignments that I have, that are purely skill building and for those though, often I hand back a rubric because then they can really see oh I didn't do that? I thought I did do that. But for ones that are more kind of building their thinking as well as their writing, they just don't seem to make a difference to students, to have it in front of them.

I: $\quad$ Is it a separate rubric for each assignment?

$\mathrm{H}$ : Yeah. Because each one is asking different things, but, the structure is the same. I take what I've asked them to do and I'm like well did they do it? ...Like I said, because I really do, one of the things that I know we hate that students hate, and 
professors, can be really bad about, is evaluating them on things that they haven't asked students to do, so I work really hard to try and be clear and honest with myself that I can't, I didn't ask them to do that, I need to change my assignment if that's really a learning objective, you know which has happened, over time, definitely. But I try; I can't really punish or evaluate a student on how well they did something that you didn't actually ask them to do. So that's why. And I do it fresh every time too even if the assignment hasn't really changed because it keeps, like I said it kind of keeps me honest in terms of what I actually asked them to do. Kind of like being in the moment you know, when you're grading.

The following passage also highlights the topic of the rubric for Hannah,

I: How will you grade this assignment?

H: Did they do this? (Pointing to the first part of the assignment sheet) And did they do this? (Pointing to the second part of the assignment sheet).

I: $\quad$ The first and second parts?

H: $\quad$ Yeah the first and second in terms of, did they use at least six readings from [Textbook A] because that's a place where they've fallen short because they go on and on about their thoughts and tend to fall a little bit shorter with the evidence part, which I just kind of cross myself for in writing in general. So I look for that and then I'll go on to see how they do with [Textbook B]. And I'm actually curious about this because there were students who expressed not liking it or being sick of it, or he had an agenda, which I find hilarious in a class called Guiding Civilizations. Yeah I'm curious. In the past, students have really really liked that book across the board and they really like talking about themselves as guides in relation to the guides he talks about. So anyway if they do these two 
things with their subsets then that is what earns a $\mathrm{C}$ and it goes up from there based on how well they do that.

I: $\quad$ Do you have a rubric for this one?

H: $\quad$ That was it.

I: $\quad$ So how would you then determine the grades?

$\mathrm{H}$ : If they meet all of those points that puts them at the $\mathrm{C}$ component, and then one of the things I struggle with as someone who grades is the power of my own expectations so I have to, because I just want to give A's to anybody who's done, just put a half ass effort into it. So for me what I have to watch myself on is that. And I've graded so many papers that you just, you know the difference. B is where they've done things, and it's pretty clear, almost all clear but depending on the student what's going on or wrong, they didn't go in depth very much. Their language isn't particularly clear, and the difference between that and an A is the student who does. Where you don't have to do any work to read it. I try in my mind, I have to remind myself. Like an A is an excellent paper. That is an excellent piece of writing. And that's what an excellent piece of writing is.

Hannah's clear description of how she evaluates assignments, however, did not match field notes that I collected in the classroom two days after this interview just prior to when assignments were handed back. While there was not a physical rubric written on the board, what was given on a projected word processor was a dictation of feedback for the essays, which read,

Overall, I was very impressed with the essays

Essays that didn't do well did not address the readings

When you see my remarks, this means: 
? I don't know what you are trying to say

Awk the sentence structure is fouled up

More or dev means you started a good idea but didn't follow it through so it doesn't make sense (as is)....

...I know you are all working on your second essay. The papers that earned the highest marks are those that address each question asked, incorporated thoughtful reflection, evidence/connections to the text (as appropriate; not just all from one section...), and had been proof-read.

Like I said, the majority of the papers were good to very good

A physical rubric or specific grading criteria was never handed out in class or written on the board. What was given, rather, was a series of codes for feedback; during the interview, Hannah mentioned specific grading components with markings to check if they had fulfilled a requirement and to what degree. Therefore this result from the data suggest that there was a mismatch between what the teacher thought she presented as grading standards and what students were given in terms of assessment procedures. The following section highlights the difference between the teacher's and the student's assumptions about assessment of writing assignments.

\subsection{Ubah's Account of Assessment}

Data from interviews with Ubah produced 22 indices for the category of Evaluation, with all marks in the subcategory of Grading. 0 were produced for Rubric. This result showed the discrepancy between the teacher and the student between how the writing assignments would be graded. To Ubah's awareness, there was no rubric or 
explicit grading criteria. Rather, assessment of writing assignments meant showing that the reading tasks had been completed, and not to a particular degree. Ubah stated, The main thing she's going to look at it is if we really did what the assignment requires. She's going to obviously look if we did all the first part and the second part and how we related to the readings, the examples we used, and the more quotes and the more information you use from the reading is the more that she will know that you actually did that reading and you understand and so basically she's just looking if we did the requirements of the assignment...I don't know I did everything that she asks me to do but it depends on how she views and how she sees my paper like it kind of depends. If she thinks I completed everything that she asks me to do, if she thinks that I used less quotes, if she thinks that maybe I didn't introduce the quotes, a lot of things that teachers look at it even though they don't tell you in the assignment, so it depends. I don't know. But I feel like in my opinion I got B+. I could be wrong but yeah.

In the second interview regarding the second writing assignment, Ubah again stated, "I just I don't know. I don't know how she reads how she'll grade it." Ubah used the assignment sheet to determine what the assignments "required," and used them as a checklist to add what she hoped would be just the right amount of quotes. For her, using enough quotes and using them properly weighed heavily on her judgment of assessment procedures. She did acknowledge, however, that there are more things teachers evaluate that they do not mention, meaning there was a level of mystery in evaluation criteria. Ubah did not know that a rubric or explicit grading criteria existed for assignments, since they were never given out in class or written on the board. Despite not fully knowing how the Hannah would evaluate the assignments, Ubah did mention in the last interview that 
since she had experience with Hannah's grading style, the evaluation was clearer to her for the last writing assignment: "I kind of get used to what she wanted from that from the previous papers, so I didn't find it difficult writing after understanding what she exactly wants this paper." By the last assignment, writing for the teacher had become less mysterious and Ubah could navigate her writing to better suit the teacher's expectations. In terms of what the teacher and what the student assumed about assessment of the writing assignments, results from interviews with both participants suggested that there was a discrepancy between how the teacher said she graded and how the student thought she would grade, which ultimately created an ambiguity of assessment where the student's only means of navigating evaluation expectations was time in the class; at the end of the semester she seemed to understand more of how she would be evaluated due to practice within the course, and not from written or verbal explanations of a rubric. This point illustrates the socialization of the learning process. In the short ten weeks of the course, Ubah began to navigate the course and "get used to" expectations in the course. In the next section, I will discuss the social and cultural factors that emerged from my data that provide a deeper understanding of what expectations the teacher and the student had about writing assignments and what assumptions they made about assessment. The following results were important factors in how both participants approached and dealt with writing assignments in the course and help answer my research questions in more complete detail. 


\subsection{Professor Hannah's Comments Regarding Student Strategies of Assignment Interaction}

For the category of Student Interaction With Assignment, 36 indices were yielded in the data from interviews with Hannah. Within the category, the breakdown of indices among subcategories was the following: Process (10), Experience (2), Time (10), Reading (15), Preparation (2), Understanding (4), ESL (6). Additionally included in this section of the results is the last category of data, Background, which produced 27 indices. These were distributed evenly between the two subcategories of History and Education, which were 27 each. The total for both categories combined was 63, making this the largest category with data produced. The large amount of data produced in these categories, therefore, played a substantial role in illustrating the expectations Hannah had about assignments and the assumptions she made about assessment in the course.

Data from the interviews with Hannah revealed that the three most salient themes were Process, Time and Reading. That is, how students dealt with assignments outside of class and how much of the course readings they did greatly affected their ability to follow the assignment expectations that she had set and to comprehend the assessment procedures. This meant that students who utilized resources such as the writing center or meeting with the instructor outside of class for extra assistance in decoding the assignment sheet had more of an understanding of what was expected in the assignment and how they would be evaluated. This took the form of one-on-one meetings with students outside of the class, whereby the instructor would discuss the assignment sheet individually and also show the student how to log into the writing center website and schedule an appointment with a tutor. Since the instructor's background included being a 
graduate tutor in the writing center at the university, she most often encouraged students to utilize that resource to ensure their writing matched her expectations of the assignments. Additionally, brainstorming, outlining the essay before writing, drafting, and proofreading before submission also added to students' decoding process. According to Hannah, students who took the time to fully consider the assignment sheet and follow those steps of the writing process understood the expectations more than students who relied on the assignment sheet alone or verbal explanation in class.

What was interesting to note was the corresponding data results for the subcategories of Process and Time. For Hannah, students who physically spent more time with the assignment sheet and more time with the reading and the process of writing understood her expectations more fully. As she pointed out,

I typically say for a student who doesn't struggle with reading or writing, I would say [it takes] two hours per page [to write]. Not just to draft but kind of the whole thing. So for something like this an easy ten hours would get you, it would get you a really good grade again if you were doing all the steps like you had done the reading and taken the time to make those connections and check the assignment sheet then revise it and then work with somebody to help you edit it or help you proofread it, that kind of thing. And I think that's what ends up being the problem is students aren't strong writers and need that full ten hours don't put in that ten hours. They just, they all put in the amount of time they put in regardless of where they're at on what a strong writer they are, and a lot of times even the strong writers will put in a little extra time because they understand the value of getting it done maybe, especially something like this that I hand out way in advance, getting it done to a point and then leaving it and coming back to it to revise and edit. But 
folks that aren't as strong don't realize that if they just actually put in that time it would make such a big difference.

Therefore, along with understanding the assignment sheet, there was also a level of understanding of the process that needed to happen for students to fully comprehend what was expected of their writing assignments. While the instructor commented that she had once conducted her own experiment where she added the estimated time of completion directly on the assignment sheet, she felt that this did not add to students' understanding of the writing process and assignment expectations. For this course, writing time and process expectations were not listed in the course syllabus or the assignment sheets. In the next section, I will explain the results from Ubah's verbal data regarding her individual strategies to interact with the assignment.

\subsection{Ubah's Strategies of Assignment Interaction}

Results from interviews with Ubah produced 62 indices in the category of Student Interaction With Assignment and were dispersed as follows: Process (28), Experience (2), Time (12), Reading (19), Preparation (1), Understanding (29), and ESL (8). Similar to Hannah's results, Ubah's interview data had large indices in the subcategories of Process, Time, and Reading. However, the subcategory of Understanding produced the largest number of data indices.

As with Hannah, Ubah often discussed the process of writing in order to fully grasp the assignment expectations. For her, this meant asking other classmates about specific assignment sheet components, consulting with the writing center, checking with 
her work colleagues, and asking for help from her siblings. She enlisted the help of several members of her personal life in order to succeed in the class. In other words, she created a world where those members became her resources to help her navigate the assignment sheet and assessment expectations in the course. She explained, “...I had a lot of problems and I was at her [Ubah's sister's] house and working on it so that's why she help me because she lives in Beaverton and I live in North Portland so it's difficult all the time to visit her." Later, she also commented,

This lady her name is Claudia, I am in her program. She is the executive of this nonprofit...and I am also in her program...so if I need help I would just, because we're close, so I will just go to her house and she will help me understand what the chapter is all about then when I write it in my own words that's how I use it in my essay. Because in order to use it in the essay you need to understand the chapter you know you need to show her that you read so I will just take the main idea of the chapter and then relate it into my essay.

Additionally, Ubah visited the writing center on a regular basis in order to receive verbal feedback from tutors. Ubah also practiced every assignment by outlining or free-writing. When she outlined, she checked her ideas with the reading from both textbooks and with the assignment sheet. In doing this process for every assignment, she could use a mental checklist to make sure she had done everything that she thought the assignment was asking her to do.

Sometimes like even though I make outline, sometimes those kind of assignments it really doesn't help me so I just start writing and put in all my thoughts on there and then going back later and just seeing if I did the what the assignment requires, and make it 
more organized and more clear because this one I didn't make any outline I just started writing because if I think about a lot of what I'm going to write I'm just going to waste a lot of time so I just start writing because I think that it's easier for me. Like the first essay was clear of what I'm going to write so I had an outline but this one I just start writing because it's complicated.

Time also played an important part of Ubah's interaction with the writing assignments. As Hannah mentioned, being able to complete the assignment to meet the expectations also meant allowing oneself the time necessary to complete it well. Results from Ubah's verbal data confirmed this notion, as she was aware of time constraints in conjunction with her navigation through the assignment. She commented,

I had two weeks. It was due March 16 right? So I didn't start the day she give us, I started I think it was a week later. So this paper I did it in half the time to do it the last whole week, so the first two days I wrote it down and put all my ideas. So I was just doing a little bit. But by the time I finished it it had come in a way that I thought it makes sense in the context and what she wanted us to do it, so I use more than the quotes that she ask us to use it so I thought it was past what she asked us to do it so the first part was supposed to use six chapters so then just six chapters I use and a lot of them kind of supported my idea of what I was talking about in the paper because we were defining what I think my theory of civilizations you know what I think civilization is. So I thought that six chapters supported my idea of what civilization should have really well. So there was a lot of quotes in that chapter and I find examples in my own experience in civilization kind of support that as an example so I thought it was good. 
Ubah always gave herself a substantial amount of time to understand the assignment sheet along with refine her writing prior to turning the assignment in. This allowed her to interact with the assignment over time and to have the chance to utilize the members of her community as resources that could aid her in completing her assignments to match the expectations. Even though Ubah often spoke of the importance of reading so that she could match her writing to the assignment expectations, Ubah admitted she often did not do the readings, due to lack of time. When she did, however, she made notes and highlighted in her book often so that she could more easily find quotes and refer back to the reading to make her paper stronger. This strategy also helped Ubah in navigating the assignment sheets; as mentioned in sections 4.3 and 4.4 adding examples from the textbooks was a key aspect in carrying out the assignment and assessment expectations. While Ubah did take the steps necessary in this course to navigate the assignment expectations, she commented often that she did not understand the readings as well as the assignment and assessment criteria, which is one more reason she took notes in her textbooks for the readings she did complete and asked members of her personal life to help her. During one particular instance, Ubah did not understand how she would write her paper to fit in the page length requirement. What she did to deal with this, may have been considered unconventional. She explained,

The assignment was completely very confusing but I can't hand it in an essay I'm talking about my experience and then all of the sudden 9 different skills. You know if someone were to read my essay they will just get confused like what is she talking about I thought she was talking about her experience. So I mean, I just like while I was talking about the 
9 different skills I was adding sentences in my own experience and just try to make it clear you know this is the skills that's important for leaders and this is how I use in my time in leadership. So I was trying to kind of remind myself of guides what I was talking about at the beginning because they are completely two different things. So I just I don't know...when I finished it I thought I write it in a way that kind of works a little bit just connecting things together and even though the second part we didn't supposed to tie it back in our experience but just to make it a smooth transition so the first part of the essay to the second part at the end or at the beginning I will say something about my experience and then go right into that with the skill I pull out from the actual chapters. And then at the end I just talk about the one that was hardest and the one that was easy for me. Yeah. It was like, the hardest part was just to keep it in 3 pages. That was really hard. I started in double space and then when I finished just I had 6 almost 6 pages and then I was like really having like anxiety and then I just read the assignment and I saw that word [preferred] and so I just thought single spaced.

For formatting, the assignment sheet read, " $\sim 3$ pages, Times New Roman, 12 point font, 1 inch margins, double-spaced (preferred)." This instance illustrates the chance that Ubah took in her lack of understanding the assignment; she could not keep her essay within the page length requirement, so, utilizing the word "preferred" in parentheses, her strategy was to make the essay understandable — write it in a page length that worked for her.

While the subcategory ESL had relatively low indices as compared to others in Student Interaction with Assignment, this can be explained more clearly in relation to Ubah's background - both her personal history and her educational experiences, that 
affected the way she navigated assignment and evaluation expectations; those results are discussed next.

\subsection{Ubah's Background Factors That Affected Expectations}

Since results from the category of Background included 52 indices, this was an important factor in the way Ubah understood assignment and assessment within the course. Within this category, History produced 44 indices and Education produced 36, which shows that this area was of particular importance-Background was the second largest category of data, behind Student Interaction With Assignment. Results from this category included what resources Ubah came to the class already having, and what access she had to particular academic literacy. As mentioned in the previous chapter, Ubah came to the United States as a refugee who had only completed education up to the fifth grade. In the time she was in the US, however, she enrolled in school and took ESL classes at a community college where she practiced writing assignments. She participated in Avid courses through high school (courses that focus on study skills in preparation for entering college), and took Senior Inquiry during her last year of high school, which fulfilled the requirement for Freshman Inquiry at Portland State University. Additionally, during this particular quarter she was enrolled in Writing 121 while taking Guiding Civilizations. All of these experiences served as practice in navigating academic assignments, and in particular, writing assignments. When discussing how she thought of outlining as part of her writing process, Ubah explained, 
...What I learned in the senior inquiry was to have an outline of your essays and it really helps us. It's just makes it clear in a thesis writing like 10 pages long essay and not reaching what the assignment requires, so I kind of set up an outline and just go in order that way because I feel it's kind of easier for me to just organize everything and just at the end find quotes that kind of support what I'm saying and relate back to my own experience in life and back to the readings and just compare and contrast what all what that is.

Ubah had practice with understanding how to deal with writing assignment expectations coming into the course, which therefore gave her more cultural resources to, for example, note the "preferred" expectation of double spacing, and instead choose to go against the preference and type single-spaced in order to adequately complete the assignment.

Even through coming to the class with existing cultural resources allowed Ubah to think about assignment expectations more completely, this did not come without consequences. Due to the high level of interaction she had with assignments over the semester in all of her classes, her anxiety level peaked and she moved back to her parents' home after the fifth week of classes. While this was not an initial component within the results of my data, it is important to note that despite Ubah's apparent success in navigating the academic writing assignment in Guiding Civilizations, she did have internal struggles with managing in academia so much so that her assignment-induced panic attacks led her to move out of the dormitory that her scholarship paid for, and into her parents' home in North Portland. While her background - her personal history and her previous education — had helped her and now gave her the tools to interact with 
assignments and understand assignment expectations, it also led her down a high-risk path in terms of her personal welfare.

\subsection{Summary of Results}

In this chapter, I have given a side-by-side list of the numerical results from interview transcripts that display the number of times each participant remarked about a category or subcategory (theme) related to the assignment sheet expectations and evaluation expectations. I then discussed Professor Hannah's account of assignments in section 4.3 and in section 4.4 I gave Ubah's account of assignments. Following these, I discussed Professor Hannah and Ubah's accounts of assessment in sections 4.5 and 4.6. After these, I detailed both participants' comments regarding student strategies of assignment interaction in sections 4.7 and 4.8. Finally, section 4.9 dealt with Ubah's background factors that affected her expectations within the course. The results given address my research questions as follows:

1. How do the assumptions that NNES undergraduate students make about specific attributes in SINQ writing assignments compare with those of their teachers?

Particular assignment components within the category of Assignment Expectations (Summarize, Examples, Reflect, Critical Thinking, Theory Application, and Organization) were organized in this chapter as Professor Hannah and Ubah's Account of Assignment Expectations (Section 4.3). Within this category, results from verbal data were reasonably comparable with similar or same numbers of indices marked within each subcategory. Both participants had similar notions of what was expected based on the 
written assignment sheets. This suggests that while the assignment sheet was of concern — both participants utilized the assignment sheet, referred to it specifically in interviews, and consulted the document multiple times over the course of the term, interpretations of the assignment sheet itself did not yield particularly different levels of understanding. While I at first thought comments about specific attributes on assignment sheets would comprise the majority of data for this study, what emerged was how the student interacted with the assignment sheet, and what she did with the attributes on the assignment sheets. In other words, how the student approached the assignment, and likewise how the professor believed students should approach the assignment, produced more comparable results as they related to the expectations of writing assignments within the course. This also illustrated that despite the literature on this topic as presented in chapter 2, critical thinking was not a prominent theme that emerged from the data in this study.

The most salient themes in this category for Hannah were Reading, Process, and Time, and for Ubah were Understanding, Process, and Reading. In order for the student to interpret the assignment sheet, she needed to understand the material. This naturally went with reading the course material throughout the term and completing a multi-step writing process, sometimes consisting of brainstorming, outlining, drafting, and revising. Additionally, Hannah believed that the expectations of assignment sheets began with the time students took to deal with the assignment as a whole, which meant of course reading the material, and completing a writing process. For both participants, it was not about looking at the assignment sheet and thinking about specific words or phrases. It was more 
about engaging with the material in a multifaceted manner throughout the time the assignment sheet was used.

One component that greatly affected the interaction with the assignment was Background. As previously mentioned in this chapter, results from this category, which encompassed History and Education, impacted how the student interacted with the assignments and interpreted assignment expectations. Since Ubah had had a great deal of preparation with similar assignments prior to entering the Guiding Civilizations course, she had already begun taking steps toward academic literacy. She had practiced writing similar assignments in Senior Inquiry, and also took Writing 121, a course that is not mandatory at Portland State University. Due to the practice she had before entering this course, Ubah knew how to adapt what she had already learned and apply it to a new context. She understood how to utilize members of her community as academic resources in order to maximize her understanding of the assignments and to fully utilize the writing process by drafting and revisions after being given feedback from those members.

2. How do the expectations that NNES undergraduate students have about assessment in SINQ writing assignments compare with those of their teachers? Assessment, coded as Evaluation in the verbal data, was separated into two subcategories, Grading and Rubric, as previously stated in this chapter. For Hannah, these two subcategories went hand-in-hand. A rubric to Hannah was more like a mental image of how she would evaluate students - this mental image was not given to students in a concrete fashion, however. Ubah was not aware of any specific rubric or grading criteria; rather, she saw assessment in the course as an overall check to see if students had done 
the reading and could apply it to the written assignments. The actual grading procedures, however, seemed vague to her, and she was often left thinking that grading was a sort of secret kept by the teacher and not revealed to the students. However, as she progressed through the course, the grading procedures became less mysterious due to practicing writing and "getting used to" the teacher's grading. This progression, while still mysterious, did help the student become more aware of assessment within the course and thus exhibit Ubah's elevated academic literacy—she was learning how to navigate successfully within the course and was learning how to master her role as a student within the Guiding Civilizations course.

In this chapter, I have discussed the results of my research study in terms of coded categories displayed as a side-by-side comparison of both participants' verbal data. I then went on to highlight the participants' accounts of the assignment and evaluation. Next, I illustrated how student interaction with the assignment and background affected expectations of the assignments. Last, I provided a summary of how all these points relate to my research questions. In the next chapter, I will discuss the implications of these results, explain the limitations of this study, and offer suggestions for further research. 
Chapter 5. Discussion and Implications

In this chapter, I will first provide an overview of my study and restate my research questions. I will next give an overview of the results from the research questions and relate them to previous studies. I will then give the limitations of this study and make suggestions for applications as well as offer further research suggestions.

\subsection{Discussion}

The purpose of this study was to explore the differences in expectations between a teacher and a student in a Sophomore Inquiry course with regard to writing assignments and evaluation. More narrowly, I first focused on specific attributes on assignment sheets and assessment of the associated writing assignments. Through this research, however, I discovered that it was not the specific attribute that displayed differences between the student and the teacher; rather, it was the student interaction with the assignment as a whole that illustrated differences between the student and the teacher, and inevitably led to similarities in expectations of the assignment sheet attributes. Second, I explored the differences in assessment assumptions between the teacher and the student. My experiences as a mentor in SINQ courses led me to this research study, and I was curious to see what role expectations played on Nonnative-English-Speaking Students' Writing. 


\section{Research Question 1:}

My first research question was: How do the assumptions that NNES undergraduate students make about specific attributes in SINQ writing assignments compare with those of their teachers?

This research question was explored in depth, with one NNES undergraduate student, Ubah. Here, it was the student's interaction with the assignment and her background that ultimately led to the assumptions she made about specific attributes on the assignment sheets. Results were similar within the theme of Assignment Expectations; this was due to several factors including her background and experience with writing assignments prior to entering the course. Because of her extensive background in dealing with academic writing assignments, she was therefore in a position in which she could navigate the assignment sheet. In other words, she entered the class with a significant amount of academic skills (cultural capital), which prepared her for the course (Collier \& Morgan, 2008). Even though she was a nontraditional student in the sense that she was an immigrant student who had come to the US with only an elementary grade three level education and did not have familial support within her educational endeavors, she pushed through and gained the skills necessary through her schooling in the US, including through high school programs such as Avid and Senior Inquiry.

Ubah's growing body of knowledge in academic literacy was mostly done in the American school system. She could speak and comprehend well in her native language, but since she had the majority of her education in English, this placed her in a system 
where the attitude toward knowledge was that which matched the attitude of knowledge at PSU. That is, having gone through education in the dominant society, her cultural expectations of knowledge were influenced heavily by the experiences she had in school in the US. These attitudes matched with her teachers' views of knowledge given that they had similar local educational backgrounds. Likewise, Ubah's ability to make connections with the readings, and her writing illustrated her ability to critically think within the dominant US educational system, which gave her an advantage in academic preparedness. This mirrors studies that discussed culturally shaped views of knowledge, critical thinking, and writing styles (Angelova \& Riazantseva, 1999; Ballard \& Clanchy, 1991; Collier 2001; Spack 1988, 1997).

For Ubah, navigating the writing assignment expectations was first about understanding the course material and thinking about the assignment extensively. This happened over time, by Ubah beginning the assignment the day she received the assignment sheet by consulting her course textbook and finding readings that might connect well with the assignment, and by thinking about her own life in a way that she could perhaps tie into her written work.

Second, for Ubah, navigating the writing assignment expectations was also undergoing a writing process at every assignment that included a number of steps such as brainstorming, outlining, drafting, and revising. She did this in a manner that allowed her to have enough time to complete all of the steps - she brainstormed and outlined individually, created drafts, and talked about her drafts with friends and other members of her community. Even though there was no peer review in this class, she created 
opportunities in which talking about her papers with peers outside of class became an individualized peer review system for her. She knew to do this because of her experiences in Avid and in Senior Inquiry. This key factor gave her the preparedness and established her presence in the university rhetorical community. Due to her ability to match her writing to the rhetorical community of the university system, she was able to write in a way that matched her NES peers within the course. These factors aided in her academic literacy development so much so that she was also a member of her discourse community (the university). This coincides with previously stated research studies that examined students in particular rhetorical and discourse communities - students became more successful and literate in these particular communities by being able to follow the rules and illustrate knowledge about the subject through the prescribed process of writing (Beaufort 2007; Brandt 1990; Land \& Whitley 1998).

Third, navigating the assignment expectations was reading-centered for Ubah. The more she read, the more she could make connections to the assignment and use those connections in her writing. As a result of her background and interaction with the assignment, she was able to activate her learning process within the class and begin to master the role of a student within the Guiding Civilizations course. She was also able to participate as a member of the rhetorical community necessary for the successful completion of assignments within the course. Again, having extensive practice prior to entering this class with reading and critical thinking aided Ubah tremendously to prepare for writing assignments in the Guiding Civilizations course. 
For Hannah, student interaction with the assignment was at the forefront of her expectations for the assignments as well. Reading the material was the key, in her opinion, to students' succeeding at the writing assignments. Following this, she believed that students who undertook a writing process - from brainstorming, to outlining, drafting, and revision - truly operated within the course well. To do these things needed an amount of time outside of the class that was often overlooked by students. Students who began the assignment close to the day it was handed out would often have enough time to complete the steps necessary to understand the assignment and produce a piece of writing that met her assessment criteria. As previously discussed, Ubah did in fact begin the assignments close to the day they were handed out and interacted with the assignments in a way that matched with Hannah's expectations. As a result, she was able to maneuver through the specific attributes in the assignment sheets and deduce the overall meaning of the criteria without focusing on specific words or phrases.

\section{Research Question 2:}

My second research question was: How do the expectations that NNES undergraduate students have about assessment in SINQ writing assignments compare with those of their teachers? This research question was explored in depth, with one NNES undergraduate student, Ubah, and her teacher, Hannah. The results of this research question produced two major themes: Grading and Rubric. For Ubah, grading remained a mystery for the majority of the term. She assumed the teacher would be grading assignments to check if students had read the material and had met the requirements of 
the assignment. She was unable to articulate how exactly she would be graded, however (what exactly the requirements for assessment were). Toward the end of the term, she "got used to" how the teacher graded and what she expected for the writing assignment, which displayed Ubah's process of learning and mastering her role as a student within the course (Collier, 2001; Collier \& Morgan, 2008). Regardless of her becoming accustomed to Hannah's grading style, there was still a level of ambiguity in what exactly would be graded. This result matched a previous study where evaluation judgments were never fully revealed to students, due to the teacher's own expectations that she brings with her (Ballard \& Clanchy, 1991; Land \& Whitley, 1998; Leki 1995; Vaughn 1991).

Hannah, on the other hand, believed that grading and use of a rubric were interconnected - for her, a rubric meant a mental set of guidelines by which she would assess student assignments. Even though this rubric was mentioned in interviews, it was never overtly shared with students in class. Likewise, Ubah had never seen a rubric. The expectations of the teacher and student with regard to assessment were quite different and illustrated a mismatch between participants; however, with time Ubah became accustomed to Hannah's grading criteria or style. While this illustrates the learning process and how a student may become more adept at navigating assessment, it still remained a murky component within the assignment. While "getting used to" the grading style aided Ubah in dealing with her last essay, it still remained a source of struggle and it also recreated a hierarchical structure where the teacher had control, or power over the essay, and the student remained powerless. This also coincided with past studies, which found that students in this hierarchical structure must align their expectations to the 
grading expectations of the teacher (Ballard \& Clanchy, 1991; Bourdieu \& Patterson, 1990; Collier, 2001; Collier \& Morgan 2008; Land \& Whitley, 1998, Leki 1995; Vaughn 1991). While this is generally a concern in courses where an instructor is ultimately "in charge" of issuing grades, some level of transparency on how those grades would be issued was lacking in Guiding Civilizations. Nevertheless, the more cultural capital students bring with them to a course, the better able they are to cope and deal with this relationship with regard to assessment procedures (Collier, 2001; Collier \& Morgan 2008). In this study, Ubah brought with her (and gained within this course) cultural capital that by the end of the term allowed her to partially understand what the teacher expected in terms of assessment

\subsection{Limitations}

Limits of Generalizability

Although this research study took a multifaceted approach and the results from the study answered my research questions with great depth, it is not without limitations. First, because this course met only once a week for one term, students had less time to build rapport with the teacher and get to know her assignment and assessment expectations with as much depth as a Freshman Inquiry class, which is three terms. However, this course's duration and intensity can be generalized to other Sophomore Inquiry classes, and in fact, most other classes at Portland State University, which all take place in ten weeks or one term. 
Additionally, having only one student participant limited the amount of experiences reported. If I had been able to gather rich data from the other student participants in addition to Ubah, there would have been two student participant accounts of expectations to report, which would have given the study more breadth. However, due to the lack of rich data gathered from that participant, as well as attrition from the other NNES student participant, it was not possible to do this. Since this was a qualitative research case study, one of the main points was to recount the lived experiences of the participants. Each student is different and brings to university courses wildly differing backgrounds and expectations. This study illustrated the story of a Sophomore Inquiry NNES student. She was a nontraditional, immigrant, female student who had limited schooling in her home country and really began to learn for the first time in high school within the US school system. This background highlights the same kind of diversity among NNES students that makes that student population important to explore. The amount of cultural tools and levels of academic literacy that students within this population bring with them to academic contexts varies greatly and it is crucial to comprehend this complexity in order to understand this population.

Also, it could be argued that for this study, one NES student should have been included as a participant in order to compare the experiences with that student with a NNES student. However, for the purposes and time of this research study, including a NES student simply was not manageable given the time constraints of the research project. 
Some may consider the choice to not include the mentor as a participant one of the limitations of the study. I had initially planned on examining a great deal of mentor activities relating to writing. The training I had received to become a mentor influenced this heavily and I was under the impression that all mentors would inevitably focus on writing within courses. This bias led me to believe that the mentor for this class would too focus on writing and there would be a great deal of collaboration between the teacher and the mentor to facilitate writing. However, this was not the case. As discussed in chapter three, I did a great deal of bracketing in order to reflect upon my own assumptions coming into the research study. From the bracketing I did, I learned that the mentor did not play a substantial role in the class in terms of writing. This point in fact is a notable finding to the study, not a limitation.

The teacher did not trust the mentors to teach writing, in part, because mentors were no longer recruited from English masters and bachelor degree program and were instead recruited from a number of different disciplines such as the social sciences and business. This ideology was influenced by the teacher's own experiences as a graduate mentor who earned a master's degree in English. This mismatch by the teacher's expectations of a mentor led to limited mentor involvement with the writing process. There was no peer review in mentor sessions, and no daily formal writing assignments related to the course assignments. As a result of the mentor's limited involvement in the writing assignments, I made the decision to remove the mentor from the study. Regardless of my initial bias that all mentors were engaged with writing assignment activities and teaching writing skills within mentor sessions, this simply is not true. 
Depending on the teacher or the coursework, a mentor may not be associated with teaching or tutoring writing in mentor sessions. This could be the case in many SINQ classes, which illustrates the complexity of mentor involvement within University Studies.

Additionally, since several SINQ courses are now taught by adjunct professors who may teach many different courses at PSU or who may have a full time career in a different field, it could have been worthwhile to do research in such a course. Analyzing the differences in expectations between a student and the adjunct professor could have shed light on what adjuncts are doing in their classes in terms of writing, since they may not be involved in University Studies in any other context besides teaching a designated course part time. However, it was not feasible in my recruitment stage to request either a full time or an adjunct professor. The results of this study can easily be transferrable to any SINQ course, regardless of the professor type.

\section{Methodological Limitations}

During data collection, I was able to perform member checking with the instructor and teacher regularly. I often checked in with the instructor, Hannah, after classes to clarify any points I was not sure of from my observation notes and from the written assignment sheets. For interview data, I consulted with Hannah during or shortly after the interview as I transcribed in order to clarify any information. One possible threat to validity occurred after data collection had finished and analysis was underway. While I tried to contact Ubah for member checking to clarify a few points she had made about her 
high school education and her experiences in ESL classes at PCC, I was unable to get in contact with her. The points I wanted clarification were more for general information, however, and I was able to speak with a Senior Inquiry instructor in order to clarify these points. By doing so, I minimized this threat to validity and increased credibility.

Due to my former position as a SINQ mentor, I came into the study being aware that I may bring with me researcher bias. In order to target this and increase researched credibility, I bracketed this research study. I regularly participated in peer review as I analyzed interview transcripts and assignment sheet data. I did this within a writing group in which several Applied Linguistics masters students exchanged theses and project work for feedback and comments. This group met weekly for ten weeks. By sharing my interpretations of the data regularly with peers who had little to no knowledge of University Studies, I was able to decrease the researcher effect throughout the data analysis and reflect upon the data thoroughly.

\section{Threats to Validity}

Lastly, it is important to mention validity. Specifically, the Hawthorne effect should be discussed. The Hawthorne effect, as described by Perry (2005), "Occurs when participants behave unnaturally because they know they are in a research study" (p. 246). Since I observed main session classes every week for the quarter, all students in the class knew my presence as a researcher. In order to minimize the Hawthorne effect in class, I sat toward the back of the room. I arrived promptly before each class session started so as to not disrupt students or the instructor, and I remained silent for the duration of the 
course. Also, I dressed casually with the aim of not being confused for a teacher or a mentor. On two occasions, a NES student asked me to remind him what I was studying and why I was observing the class. I responded by describing my research study, and I offered to give him a new copy of his consent form. Since I did not participate in group activities with the class, but rather sat in the back of the room and took notes, these requests served as reminders rather than attributes from the Hawthorne effect. The Hawthorne effect is important to note for this study because I did observe every main session class so I was a constant presence in the classroom. Had attempts not been made to minimize the Hawthorne effect, my role as a researcher may have been compromised. For example, the student could have viewed me as a tutor or the teacher could have viewed me as an assistant. Throughout the data collection process, I minimized the Hawthorne effect by blending in with participants and responding to any questions about the research study swiftly; observing the class provided invaluable insight and allowed me to triangulate data sources in a more holistic and focused manner. In the next section, I will discuss applications for this research, including how it can be used in courses.

\subsection{Applications}

Preparation: A Student Guidebook for SINQ Success

As mentioned previously, results from this study indicated that preparation was a key element in Ubah's ability to navigate through the course and achieve a level of academic literacy that made her succeed in the course. In fact, it was having a particular number of cultural tools and academic literacy that allowed her to be able to make that 
progression quickly throughout the term. She was able to complete Avid courses in high school and Senior Inquiry. She also took Writing 121 simultaneously with the Guiding Civilizations course. While these courses and their associated assignments inevitably prepared her for her higher education experience at Portland State University, students do enter into SINQ courses from an array of backgrounds. Some students are much like Ubah and have had the opportunity to complete Senior Inquiry at their high schools. Others are transfer students who have not taken any Inquiry classes previously and may have had limited writing practice or familiarity with writing assignments. With such a wide variety of students, this poses a problem: How can SINQ courses meet the needs of NNES students in terms of writing assignment and assignment evaluation expectations? I believe that this question may be dealt with in a concrete manner, in which students may be given the preparatory tools needed to enter and succeed within SINQ courses.

For students at PSU, a preparatory guidebook offered prior to the student entering the first SINQ course would be beneficial to students at all levels, from the student who finished Senior Inquiry or Freshman Inquiry, to the transfer student who has had no previous experience with the Inquiry style class. Even students who had inquiry course experience at the 100 level would benefit from this preparatory guidebook, because there is a level of advancement in course material and course work from the 100 level to the 200 level, regardless of the course.

Within this guidebook, a series of activities would be designed in order to maximize student awareness of the many components involved in SINQ preparedness. For example, sample assignment sheets collected from various SINQ instructors would 
be included, along with a set of comprehension questions that dealt with assignment sheet expectations. If a line in an assignment sheet reads, "Drawing upon at least four of the eight readings in Part VIII of Textbook A, describe this group's guidance environment. Use your experience to illustrate ideas from the chapters," a question could be asked: How would you "draw upon" four of the eight readings? How could you use evidence from the reading and your experience to create a strong argument for this assignment? (Write your answer here.)

Additionally, there would also be an example grading rubric with similar questions for students about how to interpret the grading components. There would also be explanations of course assignment requirements, such as how much time a student would be expected to work on an assignment, on average. Perhaps a diagram with the writing process would aid here, so that students understood how to take the many steps needed to successfully complete an assignment. Also, an area to explain the connection between reading and writing should be listed, with suggestions on how to read effectively, for example by taking notes, highlighting, and rereading for individualized comprehension checks. The guidebook would have resources throughout, including a step by step guide on how to set up an appointment at the writing center and personal accounts or reviews from visits to the writing center, made by not only NNES students, but from NES students, graduate students, and faculty who have had appointments there. This guidebook could also include a checklist for students to work with every time they had a writing assignment. By using a checklist, students would be able to see if they had taken the necessary steps to complete the assignment. 
The personal account section in the guidebook mentioned previously would be a place to discuss some strategies of successful students. This could be done as a first person narrative, whereby the section would give a fictitious SINQ situation where a writing assignment was handed out. The narrative would be a step-by-step account of what strategies an example student, such as Ubah, used to successfully complete the assignment. I have illustrated within the results of this study that for Ubah, writing socially and not in isolation gave her opportunities to consider the assignment sheet and her own writing. Utilizing members of her community, including academic members such as tutors at the writing center and non-academic members such as her sister or her colleague at the nonprofit organization where she worked, aided in her success within the class. This is one important notion that should be highlighted in the first person narrative. Even though there was no peer review in the class and students did not work on their writing in class or in mentor session, Ubah still made it a social process. This is one example of a student strategy that all SINQ students would benefit from knowing and following.

Having students work with a guidebook for a class also mirrors jobs in the real world, where often times there is a period of training where the employee must work with a similar document to complete the hiring and training process, or so that they may become experts in their particular fields. Having this information centrally located on one location would also particularly help NNES students. As previously stated, NNES students who come from different cultural and rhetorical communities may have a challenging task at interpreting assignment expectations. This type of preparation is 
transparent so that all students may enter a classroom with a certain level of tools they need to tackle and master their roles as SINQ students.

Also, the guidebook would help adjuncts, full time tenured and non-tenured faculty from other academic departments (sometimes called "shared line" faculty), and full time University Studies faculty to understand where students are in being able to navigate academic documents and course expectations. This would aid in teacher preparations and take some guesswork out of course planning. This guidebook could be electronic and available on D2L, or it could be a paperbound book given to students prior to entering the course. It could be started before the class, or it could be completed entirely throughout the mentor sessions, depending on the course.

While the guidebook contains useful information for students, mentors, and teachers, it should be noted that this training could have implications as well. Many students may not complete the guidebook prior to entering the course, which would result in needing to complete them during the mentor sessions. However, at 50 minutes per mentor session, time is of concern. Depending on the course and instructor, there may be several other activities to do that complement the main session course. Additionally, since faculty are often housed in departments across campus, working with a set guidebook may be challenging to coordinate the materials. This could be addressed by using electronic versions of the guidebooks that would be easily accessible. If done in mentor sessions, this would also correspond to one of the mentor session activities of developing computer literacy that is listed on the University Studies website ("Portland State University: Sophomore Inquiry Mentor Sessions,” 2011, para. 1). 


\section{Mentor Involvement}

Checking or going over the manual to ensure students' comprehension would naturally take time. My suggestion for this is working on it in mentor sessions. For this to happen, however, a certain level of trust needs to be in place so that mentors from all different disciplines, as they are hired, would be able to facilitate guiding the manual. From this study, I learned that mentors might not be given the opportunity to work on writing skills with students. As a result, one must wonder where students are getting writing practice: if they are not practicing writing in their main session courses or in their mentor session courses, where are they practicing? What happens in this case is that writing is overlooked. If a student took three SINQ courses in this vein, he or she would essentially have no extra writing practice needed to develop writing skills at and beyond the 200 level. This would leave students entering upper division courses with a writing deficit. More attention needs to be paid to writing development when it is feasible, so that students aren't graduating with limited writing proficiency. This development includes brainstorming, outlining, and drafting writing assignments within mentor sessions.

If faculty members are concerned about mentors having adequate writing proficiency themselves to a level where they could effectively teach writing, a more rigorous writing test could be given during the hiring process. At present, an online writing test occurs during the application process. For furthering quality standards, the tests could be administered and graded by University Studies faculty; these grades could be given to graduate mentor applicants and discussed in light of SINQ grading criteria. The assessment of the test in itself could be developed into a training module for graduate 
mentors so as to further their understanding of how writing is practiced and assessed in University Studies. Furthermore, the very nature of University Studies is interdisciplinary and has writing across the curriculum focus. Faculty members, mentors, and students all come from different backgrounds and being able to share that wide body of knowledge is at the very heart of the program. Writing instruction should have a place in this structure as well, where it should be expected that members of various academic disciplines are fully capable of teaching writing.

In many classes, mentors are highly involved in the writing process. However, as shown in this study, some classes do not have a high mentor involvement in terms of writing facilitation. Although the suggestion for mentor involvement certainly applied to this course and to others that are similarly conducted, it is important to note that mentors do have a role within SINQ courses and are trained in writing throughout their preparation course. Additionally, mentors attend writing workshops within University Studies. This training, therefore, should be utilized in a consistent manner throughout SINQ courses in order to promote their role in the classroom.

\section{Assessment Transparency}

Based on the results from my second research question about assessment expectations, transparency needs to be created such that assessment becomes more about being clear on how exactly a student will be graded, rather than on a hierarchical relationship that situates the teacher as powerful and the student as powerless. While it cannot be argued that teachers bring with them their own judgments in terms of 
evaluation, those judgments should be made available to students. In this research study, the very notion of a "rubric" carried different meanings between the teacher and the researcher. I had envisioned as a rubric as a piece of paper with a total point value and point breakdown based on specific components that was given to students. However, the teacher had envisioned as more of a mental checklist. Additionally, the student did not know what a rubric was. For this area of writing assignments, there needs to be a level of understanding between the teacher and the student. For each assignment, grade breakdowns should be given to students with explanations of how their work matches, or does not match, the grading criteria. The grading rubric does not need to include specific point values if it does not match the essence of the class; however, grading criteria should be clearly presented in a way that they can be discussed by the teachers and students so that students are aware of grading procedures. Students could be made ready for these types of rubrics in the manual as I discussed previously. This kind of uniformity among grading procedures would alleviate some of the mysterious notions of assessment that exist in higher education and would also create more equity for students to see and understand what they did on the assignment and how it compares to the teacher's expectations. This should be a standard that all SINQ courses follow in order to maintain consistency within the program and demonstrate to students that they know how they will be graded.

Additionally, this standard would build consistency among adjunct, full time tenured and non-tenured faculty from various academic departments, and full-time University Studies faculty-led classes. Often adjuncts may only teach one class at 
Portland State University. These teachers may not have access to grading procedures and assessment experience. If example rubrics and grading criteria for teachers were compiled into a training manual or even a document storage bank, teachers would have access to different styles and types of rubrics and other types of grading procedures. Explanations of the assessment could be created and placed along with the documents containing grading criteria examples, so that teachers could have a better understanding of how to use them within classes. Training through a manual, access to a document storage bank, or workshops dealing with assessment procedures and rubrics would add to the clarity and understanding of assessment expectations within SINQ courses.

Professional development for faculty members does occur in University Studies; the abovementioned suggestions for applications could be included among those professional development sources. Again, even though professors often come to SINQ courses from other departments or other fields outside teaching and outside Portland State University, the applications of assessment transparency can be extended beyond University Studies to other departments, programs, and institutions. This application suggestion serves the needs of students and instructors at a much broader level, and may be incorporated into training and workshops in a variety of settings and for a variety of learners.

Creating materials for the above applications would be an invaluable project for someone interested in developing University Studies or higher education training tools. Following the creation of these tools, a study should be done to explore the benefits of the guidebook. A mentor or faculty member within the University Studies department 
would be an ideal candidate for this endeavor due to the insider knowledge of the program, assignments, and assessment procedures.

\subsection{Filling the Previous Research Gap}

The previous studies that were examined in chapter two explored several issues related to NNES undergraduate student writing, including graduate writing samples, essay test graders, writing center concerns, and longitudinal coursework. Through the examination of a single undergraduate general education course, this study has illustrated the complexities surrounding NNES undergraduate student writing expectations. The study was focused on NNES undergraduate students and their teachers; primarily, I highlighted the differences in expectations between Hannah, the teacher, and Ubah, a NNES undergraduate student. The SINQ course in which this study took place is representative of various courses in higher education that are one quarter in duration, have a different instructor every course, and also have various assignments associated with them. This current study bridges the gap in the research presented, which dated from 1988 to 2008. In the next section, I will highlight suggestions for future research, based on this research study.

\subsection{Suggestions for Future Research}

The results of this study certainly added to the understanding of expectation differences with regard to writing assignments in SINQ courses. However, more research needs to be done to fully deal with the issues surrounding NNES writing in University 
Studies. First, a longitudinal study would be beneficial for understanding the needs of NNES students in SINQ courses. A study that followed one such student for three terms in three different classes could add to the understanding of academic literacy attainment. Second, researching a course where the mentor was pre-established as a writing facilitator would be beneficial to study, so as to shed light on how mentor sessions that do focus on writing impact NNES students' understanding of writing assignments and assessment. Third, a research study focused on writing assignments that included data from assignment sheets, the syllabus, rubrics, and writing samples of NNES students in SINQ courses would be valuable for comparing NNES student output with writing expectations in University Studies courses. In all of these suggestions for future research, SINQ courses provide the setting of the study. As mentioned previously, SINQ courses are the stepping-stones to upper division courses. The number of research projects that could be done regarding NNES student writing are many; in order to gain more insight into NNES student concerns in SINQ classes, more research in these courses needs to be done.

\subsection{Conclusion}

This study examined the role of expectations on a nonnative English-speaking student's writing within one SINQ course during winter 2012. The results showed several differences between how the student interacted with the assignment and how she viewed assessment, and likewise how the teacher viewed these components. Moving forward, it is crucial to understand that students, regardless of their linguistic background, need 
support in attaining academic literacy such that they may move through Portland State University's core curriculum with success. If we are to promote knowledge through inquiry, we must adequately equip students with the tools necessary to do so. This must be done by preparing students and through having transparent assessment methods, so that as students increase their cultural capital throughout higher education, they will also be able to successfully navigate other settings beyond the classroom. 


\section{References}

Angelova, M. R. A. (2000). "If you don't tell me, how can I know?": A case study of four international students learning to write the U.S. way. Communication Abstracts, 23, 4, 491-524. Doi: 10.1177/0741088399016004004

Ballard, B \& Clanchy, J. (1991). Assessment by misconception: Cultural influences and intellectual traditions. In L. Hamp-Lyons (Ed.), Second language writing (pp. 19 35). Norwood, New Jersey: Ablex Publishing Corporation.

Beaufort, A. (2007). College writing and beyond: A new framework for university writing instruction. Logan, UT: Utah State University Press.

Bourdieu, P., \& Passeron, J. C. (1990). Reproduction in education, society, and culture. London: Sage Publications.

Brandt, D. (1990). Literacy as involvement: The acts of writers, readers, and texts. Carbondale: Southern Illinois University Press.

Brown, A. J. (2002). Perceptions of good writing: An examination in the Writing Center (Unpublished master's thesis). Portland State University, Portland, Oregon.

Creswell, J. W., \& Miller, D. L. (2000). Determining validity in qualitative inquiry. Theory Into Practice, 39(3), 124-130.

Collier, P. (2001). A differentiated model of role identity acquisition. Symbolic Interaction, 24(2), 217-235.

Collier, P., \& Morgan, D. (2008). "Is that paper really due today?": Differences in first generation and traditional college students' understandings of faculty expectations. Higher Education, 55(4), 425-446. 
Hamp-Lyons, L. (1991). The writer's knowledge and our knowledge of the writer. In L. Hamp-Lyons (Ed.), Second language writing (pp. 51-68). Norwood, New Jersey: Albex Publishing Corporation.

Land, R.E. Jr. \& Whitley, C. (1998). Evaluating second language essays in regular composition classes: Toward a pluralistic U.S. rhetoric. In Spack, R. and Zamel, V. (Eds.), Negotiating academic literacies: Teaching and learning across languages and cultures (pp. 135-144). Mahwah, N.J: Lawrence Erlbaum Associates.

Leki, I. (1995). Good Writing: I know it when I see it: Matching student and teacher perceptions. In D. Belcher and G. Braine (Eds.), Academic writing in a second language: Essays on research and pedagogy (pp. 23-46). Norwood, NJ: Ablex Publishing Corporation.

Leki, I. (2006). Negotiating socioacademic relations: English learners' reception by and reaction to college faculty. Journal of English for Academic Purposes, 5, 2, 136152. Doi: $10.1016 /$ j.jeap.2006.03.003

Leki, I. (2007). Undergraduates in a second language: Challenges and complexities of academic literacy development. New York: Lawrence Erlbaum Associates.

Perry, F. L. (2005). Research in applied linguistics: Becoming a discerning consumer. Mahwah, N.J: Lawrence Erlbaum Associates.Portland State University: Office of Institutional Research and Planning. (2011). Retrieved from http://www.oirp.pdx.edu/source/fact11s/3 $20 \quad 1 . h t m$ 
Portland State University: Our Mission. (2011). Retrieved from http://www.pdx.edu/mission.html

Portland State University: Profile. (2011). Retrieved from http://www.pdx.edu/profile/student-population

Portland State University Studies: Sophomore Inquiry Mentor Sessions. (2011). Retrieved from http://www.pdx.edu/unst/sophomore-inquiry-mentor-sessions

Portland State University: Transfer Students and University Studies. (2011). Retrieved from http://pdx.edu/unst/transfer-students-and-university-studies

Portland State University Studies: University Studies Goals. (2011). Retrieved from http://pdx.edu/unst/university-studies-goals

Silva, T. (1992). L1 vs L2 writing: ESL graduate students' perceptions. TESL Canada Journal, 10(1), 27-48.

Spack, R. (1988). Initiating ESL students into the academic discourse community: How far should we go?. TESOL Quarterly, 22(1), 29-51.

Spack, R. (1997). The acquisition of academic literacy in a second language: A longitudinal case study. Written Communication, 14(1), 3-62.

Vaughn, C. (1991). Holistic assessment: What goes on in raters' minds? In L. Hamp Lyons (Ed.), Second language writing (pp. 19-35). Norwood, New Jersey: Ablex Publishing Corporation. 
Appendix A: Coding Chart for Assignment Details

\begin{tabular}{|l|l|l|}
\hline \multicolumn{1}{|c|}{ Category } & Text & $\begin{array}{c}\text { Page } \\
\text { Number/Location }\end{array}$ \\
\hline Assignment & & \\
\hline Requirements & & \\
\hline Assessment & & \\
\hline Organizational & & \\
\hline Substantive & & \\
& & \\
\hline Theoretical & & \\
& & \\
\hline
\end{tabular}


Appendix B: Open Codes for Transcripts

\begin{tabular}{|c|c|}
\hline Assignment Expectations & Evaluation \\
\hline - Describe & - Points \\
\hline - Interpret & - Grading \\
\hline - Evaluate & - Culture \\
\hline - Analyze & \\
\hline - Clarity & \\
\hline - Authenticity & \\
\hline - Focus & \\
\hline
\end{tabular}


Appendix C: Categorical Chart for Transcripts

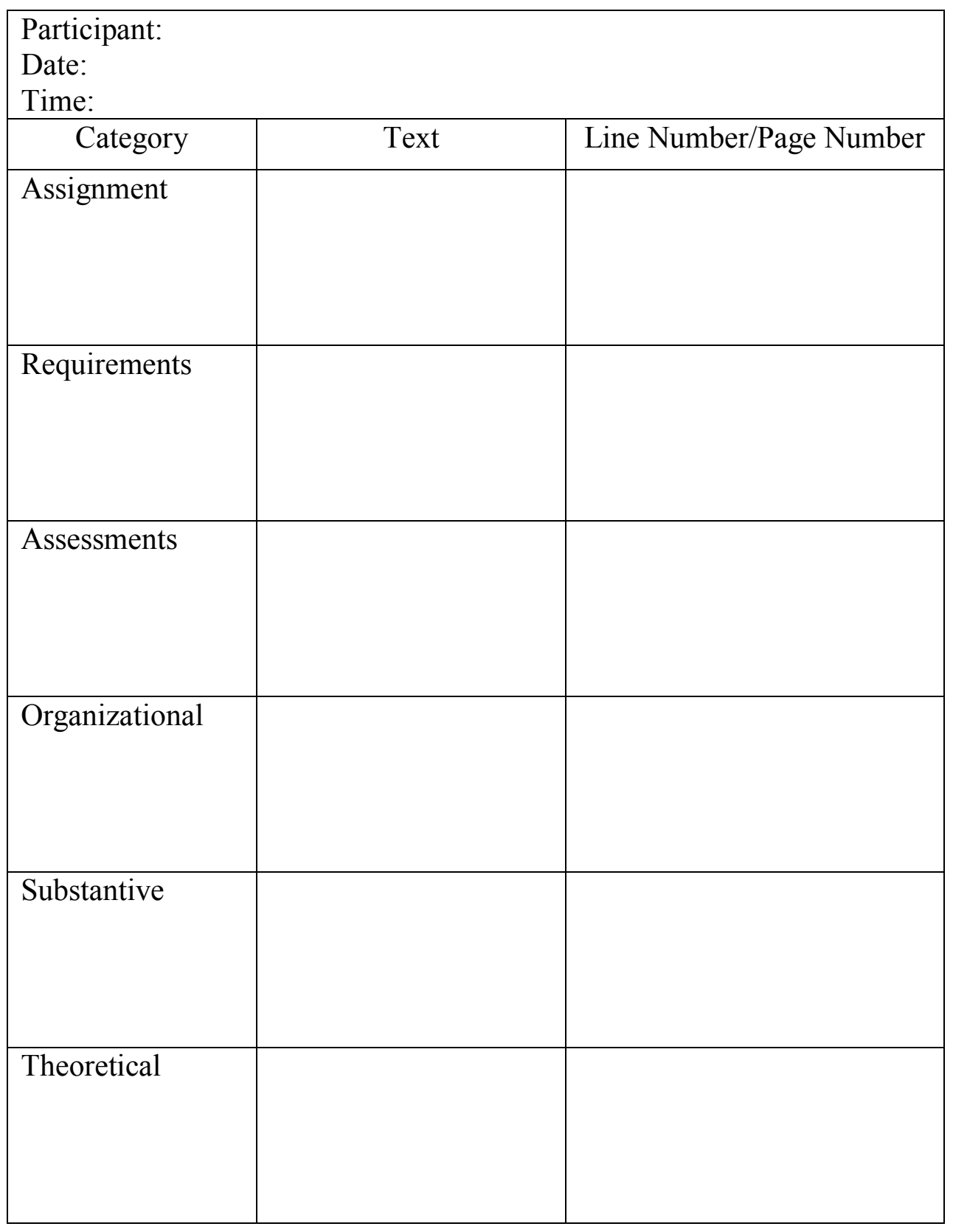


Appendix D: Email to SINQ Instructors

Hello, my name is Sara Van Dan Acker and I am a graduate student in the department of Applied Linguistics. I have also been a University Studies Peer Mentor - I mentored Family Studies last spring and Popular Culture in the summer. I will be doing a research project during winter term about nonnative-English-speaking students' writing in Sophomore Inquiry classes at PSU, in partial fulfillment for a master's degree. I hope to learn what expectations students, instructors, and mentors have about writing assignments and evaluation. Annie Knepler is on my thesis committee, and we met yesterday to discuss courses that might be a good fit and instructors who may be interested in my research project. Your name came up, in association with the SINQ class you are teaching in the winter Course Name Here. I am wondering if you might have a few minutes to talk with me over the phone or to meet in person so I can describe my project in a little more detail. If you were interested in the project, I would ask the graduate mentor to participate as well. Thank you for your time and consideration. I hope to hear from you soon.

Sincerely,

Sara Van Dan Acker

Graduate Student, Department of Applied Linguistics 
Appendix E: Questionnaire for PSU SINQ Students:

1. How old are you now?

2. What gender do you consider yourself to be? (Please circle one) Male Female

3. As of today, what is your academic standing? (Please circle one)

Freshman Sophomore Junior Senior

4. What is your major?

5. Do you consider yourself to be bilingual? (Please Circle one) Yes No

6. Is English your first language? (Please circle one) Yes No

If the answer is yes, what was your first language?

Thank you for completing this survey!

If you would like to participate in this research project about writing in SINQ courses, please write your full name and your email in the lines below:

Name

Email Address 
Appendix F: Open Coding For All Interviews

\begin{tabular}{|c|c|c|c|c|c|c|c|c|c|c|}
\hline Category / Subcategory & Code & $\begin{array}{c}\mathbf{H} \\
\text { Total }\end{array}$ & H1 & H2(a) & H2(b) & H3 & $\begin{array}{c}\mathrm{U} \\
\text { Total }\end{array}$ & U1 & $\mathbf{U 2}$ & $\mathbf{U 3}$ \\
\hline Assignment Expectations & ASE & 40 & 13 & 1 & 11 & 15 & 41 & 10 & 10 & 21 \\
\hline • Summarize & SUM & 13 & 1 & 1 & 9 & 2 & 14 & 5 & 6 & 3 \\
\hline - $\quad$ Examples & EXA & 13 & 6 & 0 & 2 & 5 & 17 & 3 & 4 & 10 \\
\hline - $\quad$ Reflect & REF & 17 & 5 & 0 & 5 & 7 & 17 & 1 & 3 & 13 \\
\hline - $\quad$ Critical Thinking & CRI & 4 & 1 & 0 & 2 & 1 & 3 & 0 & 3 & 0 \\
\hline $\begin{array}{ll}\text { - } & \text { Theory } \\
& \text { Application }\end{array}$ & THE & 4 & 1 & 0 & 2 & 1 & 4 & 0 & 0 & 4 \\
\hline - Organization & ORG & 13 & 3 & 0 & 3 & 7 & 13 & 4 & 3 & 6 \\
\hline Evaluation & EVA & 12 & 5 & 1 & 3 & 3 & 22 & 6 & 5 & 11 \\
\hline - Grading & GRA & 6 & 2 & 0 & 2 & 2 & 22 & 6 & 5 & 11 \\
\hline - $\quad$ Rubric & RUB & 6 & 4 & 0 & 1 & 1 & 0 & 0 & 0 & 0 \\
\hline $\begin{array}{l}\text { ST Interaction with } \\
\text { Assignment }\end{array}$ & SIA & 36 & 8 & 5 & 13 & 10 & 62 & 17 & 14 & 31 \\
\hline - Process & PRO & 10 & 0 & 1 & 4 & 5 & 28 & 8 & 7 & 13 \\
\hline - Experience & EXP & 2 & 2 & 0 & 0 & 0 & 2 & 2 & 0 & 0 \\
\hline - $\quad$ Time & TIM & 10 & 0 & 1 & 2 & 7 & 12 & 1 & 4 & 7 \\
\hline - $\quad$ Reading & REA & 15 & 3 & 0 & 9 & 3 & 19 & 4 & 1 & 12 \\
\hline - $\quad$ Preparation & PRE & 2 & 1 & 1 & 0 & 0 & 1 & 1 & 0 & 0 \\
\hline - $\quad$ Understanding & UND & 4 & 1 & 0 & 1 & 2 & 29 & 9 & 5 & 15 \\
\hline • $\quad$ ESL & ESL & 6 & 3 & 3 & 0 & 0 & 8 & 8 & 0 & 0 \\
\hline Background & $\mathrm{BAC}$ & 27 & 1 & 7 & 17 & 2 & 52 & 32 & 15 & 5 \\
\hline - History & CUL & 27 & 0 & 7 & 17 & 2 & 44 & 27 & 15 & 2 \\
\hline - $\quad$ Education & EDU & 27 & 0 & 7 & 17 & 2 & 36 & 21 & 12 & 3 \\
\hline
\end{tabular}


Appendix G: Essay 1 Assignment Sheet

\section{Guiding Civilizations}

Essay \#1

Due: $1 / 27$

These readings discuss how guides and guiding were thought of in the past; the traits of guides, followers, and both together; and how to guide individuals and groups. For this short essay, discuss what you think is most interesting about how guidance was viewed in the past. Explain to me why you think this is the most interesting thing by using specific examples from the text. Considering the traits of guides and supporters, which do you think most applies to your guiding style right now? Again, explain to me why you think this by using examples and quotes from the chapters. Lastly, which do you think is easier, guiding individuals or leading a group? Justify your answer using examples from the text.

Format: 2-3 pages, Times New Roman, 12 point font, 1 inch margins, double-spaced (preferred). When quoting you may use either APA or MLA formatting for in-text citations (but be consistent!) and you do not need a work cited or reference page. 
Appendix H: Essay 2 Assignment Sheet

\section{Guiding Civilizations}

Essay \#2

Due $2 / 17$

Think of a group of which you have been a part. Drawing upon at least four of the eight readings

in Part VIII of Textbook A, describe this group's guidance environment. Use your experience to illustrate ideas from the chapters. In the second part of the essay, briefly summarize the guidance skill identified in each chapter of section XI. Of these skills, which do you see as the easiest for you to practice and which do you see as the hardest to learn? Explain why you think so and use examples to illustrate your point.

Format: $\sim 3$ pages, Times New Roman, 12 point font, 1 inch margins, double-spaced (preferred). When quoting, you may use either MLA or APA formatting for in-text citations and you do not need to complete a work cited or reference page. 
Appendix I: Essay 3 Assignment Sheet

\author{
Guiding Civilizations
}

Final Essay

Due 3/16

This term you have read, reflected, and written on many theories and concepts of guidance. For the first part of this final essay, I want you to devise your own theory of guidance. A valid theory is always supported by evidence. As your evidence, draw upon at least six readings from Textbook A that support your theory. Be sure to go in-depth explaining why those particular readings support your theory (i.e., quotes).

For the remainder of the essay, compare your theory of guidance to that found in Textbook B. Again, the objective is to clearly illustrate your opinion with quotes from the text.

When using quotes it is not enough to just plop them in the middle or end of a paragraph. You must explain to the reader why you think the quote supports your idea. Otherwise, the quote is meaningless.

Format: 4-5 pages, Times New Roman, 12 point font, 1 inch margins, double-spaced (preferred). When quoting, you may use either MLA or APA formatting for in-text citations and you do not need to complete a work cited or reference page. 